\title{
Urban poverty and health in developing countries: Household and neighborhood effects
}

Mark R. Montgomery

Population Council

Paul C. Hewett

Population Council

Follow this and additional works at: https://knowledgecommons.popcouncil.org/departments_sbsr-pgy

Part of the Demography, Population, and Ecology Commons, Family, Life Course, and Society Commons, International Public Health Commons, and the Place and Environment Commons How does access to this work benefit you? Let us know!

\section{Recommended Citation}

Montgomery, Mark R. and Paul C. Hewett. 2004. "Urban poverty and health in developing countries: Household and neighborhood effects," Policy Research Division Working Paper no. 184. New York: Population Council. Version of record: https://doi.org/10.1353/dem.2005.0020 


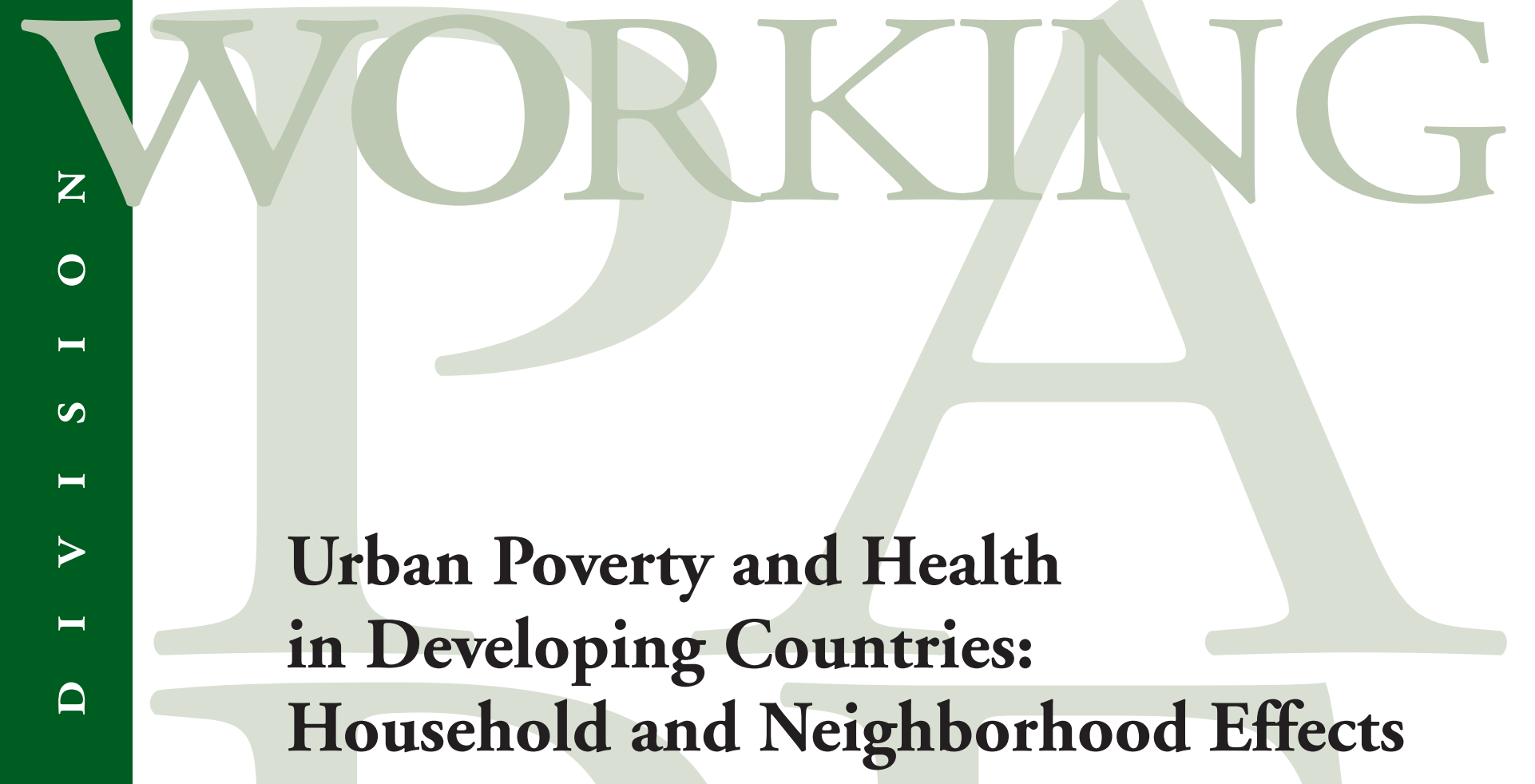

I $\quad$ Mark R. Montgomery

u

Paul C. Hewett

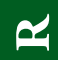

4

[I]

๑

피

电

$\gg$

U

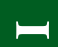

$-$

8

A

2004 No. 184 


\title{
Urban Poverty and Health in Developing Countries: Household and Neighborhood Effects
}

\author{
Mark R. Montgomery \\ Paul C. Hewett
}

Mark R. Montgomery is Professor of Economics, State University of New York at Stony Brook, and Senior Associate, Policy Research Division, Population Council. Paul C. Hewett is Associate, Policy Research Division, Population Council. Funding for this paper was provided by the William and Flora Hewlett Foundation and the Andrew W. Mellon Foundation.

This material may not be reproduced without written permission from the authors. For a list of Policy Research Division Working Papers, including those available for downloading in PDF format, see www.popcouncil.org/publications/wp/prd/rdwplist.html.

(c) 2004 The Population Council, Inc. 


\begin{abstract}
In the United States and other high-income countries, where most people live in cities, there is intense scholarly and program interest in the effects of household and neighborhood living standards on health. Yet very few studies of developing-country cities have examined these issues. This paper investigates whether in these cities the health of women and young children is influenced by both household and neighborhood standards of living. Using data from the urban samples of 85 Demographic and Health Surveys, and modeling living standards using factor-analytic MIMIC methods, we find, first, that the neighborhoods of poor households are more heterogeneous than is often asserted. To judge from our results, it appears that as a rule, poor urban households do not tend to live in uniformly poor communities; indeed, about one in ten of a poor household's neighbors is relatively affluent, belonging to the upper quartile of the urban distribution of living standards. Do household and neighborhood living standards influence health? Applying multivariate models with controls for other socioeconomic variables, we discover that household living standards have a substantial influence on three measures of health: unmet need for modern contraception; attendance of a trained provider at childbirth; and children's height for age. Neighborhood living standards exert significant additional influence on health in many of the surveys we examine, especially in birth attendance. There is considerable evidence, then, indicating that both household and neighborhood living standards can make a substantively important difference to health.
\end{abstract}


For the foreseeable future, world population growth will be concentrated mainly in the cities and towns of developing countries. According to the United Nations (2000), by the year 2030 the world's population will exceed today's total by 2.06 billion persons, of whom some 1.94 billion will be added to the urban areas of Africa, Asia, and Latin America. With these prospects in view, researchers concerned with poverty and opportunity must increasingly set their concerns in urban contexts.

What might city life imply for levels of reproductive health and for health inequalities? Using data from the urban samples of 85 Demographic and Health Surveys (DHS), we focus on three indicators of health: the unmet need for modern contraception; attendance of a doctor, nurse, or trained midwife at childbirth; and young children's height for age. The first of these, the unmet need for contraception, is closely linked to unintended pregnancy; birth attendance is a measure of the protection given mothers and children at the time of delivery; and height for age is an often-used indicator of the state of child health. Taken together, these measures describe a relatively high-risk period in the lives of women and their children. Our principal objective is to understand how such health measures are affected by urban living standards. To assess the effects, we will consider two dimensions of living standards. One is defined for the household in which the woman and her children reside, and the other for the sampling cluster in which the household resides. Holding household living standards constant, we investigate whether poverty and affluence in the surrounding neighborhood affect health.

Why are such "neighborhood effects" of interest? Debates on urban poverty in the developing world have often been framed in terms of the living conditions of slum dwellers. Estimates by UN-HABITAT (United Nations Human Settlements Programme) suggest that some 38 percent of the population of developing-country cities live in slums, with total slum populations numbering 126 million persons in Africa, 433 million in Asia, and 87 million in Latin America (Herr and Karl 2002; Herr and Mboup 2003). The emphasis on slums has been accentuated by the United Nations Millennium Declaration, which specifies a target of achieving by 2020 "significant improvement in the lives of at least 100 million slum dwellers" under the broader goal of ensuring environmental sustainability. ${ }^{1}$ But there is, as yet, no consensus in the research community on how "slums" are to be defined, and there is surprisingly little knowledge of the relationship between urban poverty overall and the living standards of slum populations. It is not known, for example, what proportion of the developing-country urban poor live in slums, nor what proportion of slum dwellers can be counted as poor in terms of income and other socioeconomic criteria. Furthermore, although the spatial concentration of poverty would seem to be essential to any definition of slums, current efforts at systematizing slum definitions (using indicators of access to safe drinking water, adequate sanitation, electricity, and security of housing tenure) have been focused on households, and have not directly taken into account the concentrations of poverty or affluence in the neighborhoods that surround households.

In its relative neglect of neighborhood effects, the literature on urban poverty in poor countries stands in sharp contrast to that concerned with the United States and other rich 
countries, where neighborhood effects have been the subject of intense scholarly interest over the past two decades. These research efforts have drawn much of their motivation from the writings of Wilson, Coleman, and colleagues on social interaction, exclusion, and social capital in poor U.S. neighborhoods (Wilson 1987; Coleman 1988; Massey 1990; White 2001; Sampson et al. 2002). A supporting motivation has emerged within the demographic realm, where multilevel analyses hold considerable methodological appeal. Neighborhood effects are a leading example of the forces operating outside households that can exert influence on household-level attitudes and behavior. Hence, on both substantive and methodological grounds there would seem ample reason to explore neighborhood effects in the cities of poor countries.

What, then, can account for their neglect? A fundamental barrier to such research is the lack of data on living standards. Because the DHS program gathers no information on household incomes or expenditures as such, measures of poverty based on these and similar surveys are limited to what can be fashioned from a few proxy variables, including ownership of consumer durables and crude assessments of the quality of housing. A lively literature has emerged in the past few years on the merits of various statistical techniques that use such indicators. We explore one of the most promising approaches for distilling the proxies into a single living standards index, termed MIMIC models, which are a variant of confirmatoryfactor analysis. In applying this method, we face one difficulty of a methodological nature: The indicators at hand are dichotomous, and standard factor-analytic techniques are inappropriate for such cases. We have developed our own estimation routines to address this problem.

The paper is organized as follows. To begin, we briefly sketch the theory of neighborhood effects in relation to health, drawing from the new report of the National Research Council's Panel on Urban Population Dynamics (2003). The paper's second section gives an overview of the models and statistical issues that must be confronted in fashioning defensible measures of living standards from the crude raw materials at hand, and here we summarize our thinking in an equation system that links urban living standards to health. The third section describes the DHS data, presenting descriptive statistics on the health measures, the basic set of explanatory variables used in the models, and the indicators of household living standards. We then compare living standards and poverty measures for households with summary measures that are calculated at the sampling cluster level, the aim being to understand just how closely household and neighborhood living standards are linked. Following this, the next section presents multivariate results for the three health measures, with the models based only on household living standards factors shown first, and models with both household and neighborhood factors following. The paper concludes with thoughts on an agenda for further work.

\section{NeIGHBORHOOD EFFECTS: A REVIEW}

Figure 1 may help to frame the issues. In the slums of Nairobi, we see rates of child mortality that substantially exceed those found elsewhere in the city, and that are high enough 


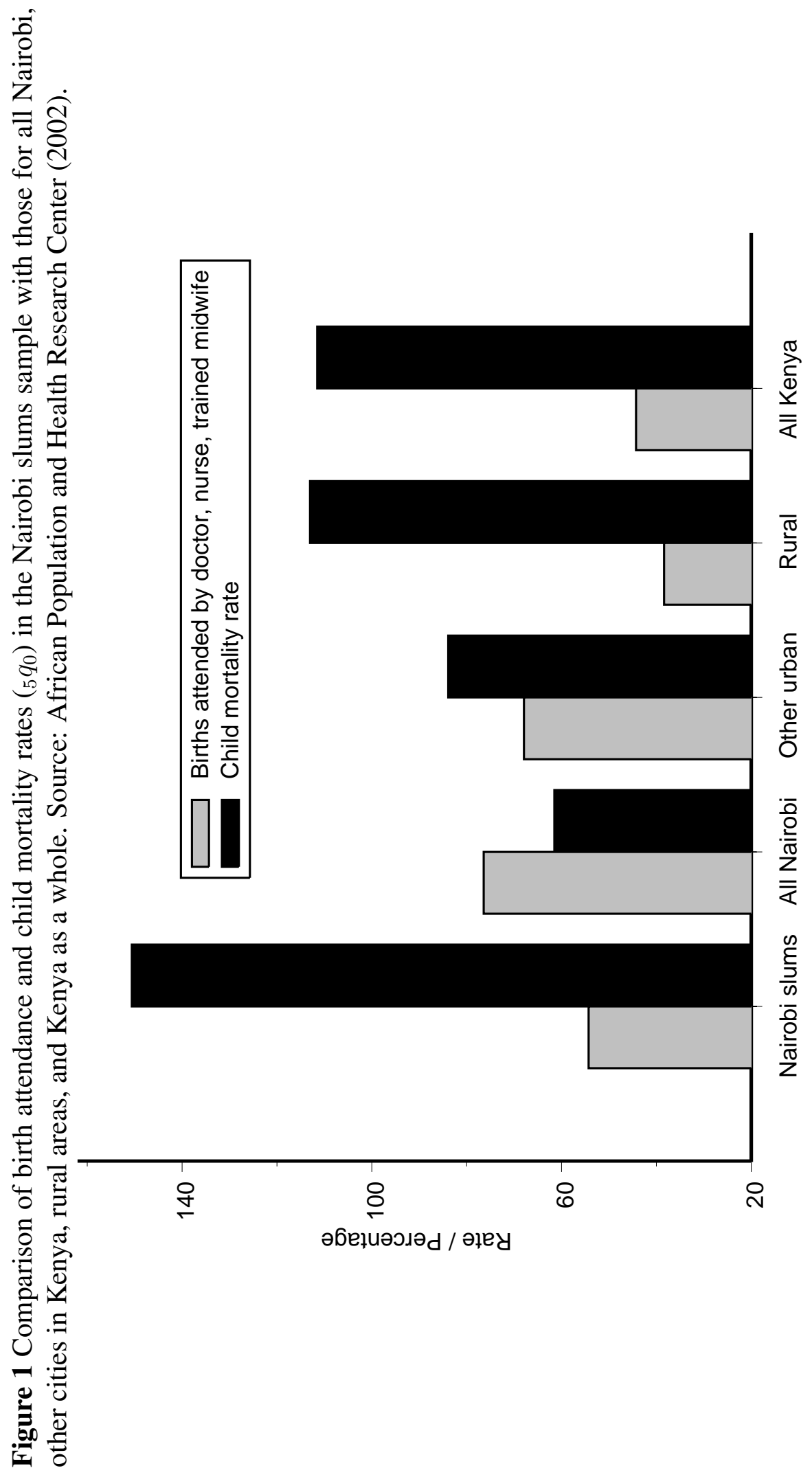


even to exceed rural rates of mortality. If urban populations have an advantage in health, as is so often asserted, then it seems that this advantage must be very unequally shared. Of course, such urban disadvantages were once widely apparent in the West: In the nineteenth century, it was not uncommon for mortality rates in urban slums to far exceed those of the countryside. In that era, it was well understood that the spatial concentration of urban dwellers put them at higher risk of communicable diseases. If anything, such urban-rural differences are more striking in today's world, because even in poor countries many cities have managed to provide the basic public health infrastructure needed to combat communicable diseases, and city populations are generally better supplied with modern curative health services. Indeed, on average, as the Panel on Urban Population Dynamics (2003) has shown with DHS data, city populations exhibit lower levels of child mortality than are found in the countryside. When one looks beneath the urban averages, however, striking differentials in health are revealed-poor city dwellers often face health risks that are nearly as bad as those seen in the countryside, and sometimes (as in Nairobi) the risks are decidedly worse. In this respect, the bars displayed in Figure 1 having to do with birth attendance convey a sense of what can be seen more generally in developing countries, namely, large health disparities between slum residents and those living elsewhere in the city, but with slum residents being somewhat better shielded from risk than rural dwellers.

Our concern in this paper is with urban populations only. Confining attention to the portions of Figure 1 that refer to urban Kenya, we recognize significant differences in health within the urban population. These intraurban inequities have received curiously little attention from researchers, but of course they will be taking on greater weight in all poverty calculations as developing countries continue to urbanize. Because the Nairobi slum populations of Figure 1 exhibit the poorest health in urban Kenya, there is a suggestion that the spatial concentrations of poverty found in these slums may apply health penalties beyond what household poverty alone would apply. But the figure does not distinguish poor households in slums from poor households living elsewhere, and it can give no clear testimony as to the effects of spatially concentrated poverty. There is enough here, however, to invite further exploration.

\section{A sketch of the theories}

We cannot do justice to the many pathways by which neighborhood and related contextual effects could influence health. In its new book, the Panel on Urban Population Dynamics (2003) provides an extensive review of these theories, with attention to their implications for neighborhood-level poverty (or living standards) and individual demographic behavior in the cities of developing countries. To briefly summarize this panel's lengthy and complex argument-much of which is dependent on empirical examples from the U.S. experienceone expects neighborhoods to matter for several reasons. Where communicable diseases are concerned, it has long been recognized that the spatial proximity of diverse urban populations can generate negative health externalities. Timæus and Lush (1995) provide a penetrating discussion of these externalities. As we have seen for Nairobi, the externalities associated 
with environmental contamination and communicable diseases could cause the health risks of slum life to rival or exceed those of rural areas, despite the generally easier access of urban residents to emergency transport and modern health services (Harpham and Tanner 1995; Timæus and Lush 1995; African Population and Health Research Center 2002).

Less-often recognized, but potentially of equal importance, are the social externalities that figure into urban life. Individual women and households are connected to others in their neighborhoods through social network ties, and along such social circuits information may flow about how to recognize and respond to health threats, and where appropriate services can be found. Of course, social network ties often reach beyond the local neighborhood. It has been argued, however, that the social networks of women and the poor are spatially constricted by comparison with those of men and the more affluent. The relative costs of travel may well be greater for the poor, and women with children and domestic responsibilities may find their daily routines largely confined to local neighborhoods (McCulloch 2003; Panel on Urban Population Dynamics 2003). Although we are aware of no recent research on social networks and the diffusion of health information in developing-country cities, the work of Behrman et al. (2001) and Casterline et al. (2001) document the network effects on contraceptive use in rural and periurban African contexts. ${ }^{2}$

Theories of local reference groups and social comparison are often invoked (if rarely formally tested) in relation to the psychosocial aspects of health. The idea is that individuals may evaluate their own circumstances by comparing them with what can be observed of the circumstances of others (van den Eeden and Hüttner 1982). Comparisons that are consistently unfavorable may provoke feelings of resentment and inequity, producing stresses and anxieties that undermine mental health. There is reason to think that such mechanisms can affect health more broadly. In the view of Wilkinson (1996: 215),

It is the social feelings which matter, not exposure to a supposedly toxic material environment. The material environment is merely the indelible mark and constant reminder of one's failure, of the atrophy of any sense of having a place in a community, and of one's social exclusion and devaluation as a human being.

Repeated exposure by the poor to such social inequities could erode their feelings of social confidence, weakening the sense of personal efficacy that is needed to assert claims to health resources and otherwise to engage in constructive health-seeking behavior.

The role of relative socioeconomic standing, as measured by individual income in relation to the income distribution of the surrounding community or wider social group, is still largely untested, especially for spatial units as small as neighborhoods (Wen et al. 2003). In U.S. research, some evidence has emerged — not always consistently-indicating that inequality at the county, metropolitan area, and state level is linked to poor health at the individual level. Very little is known of this relationship outside the U.S. context. Other social mechanisms with similar effects include those linked to residential segregation (Massey 1996; White 2001) and to local social capital (Furstenberg 1993; Aber et al. 1997; Furstenberg and Hughes 1997; Astone et al. 1999). 
Much of this literature has emphasized the spatial concentration of poverty, but the effects of spatially concentrated affluence are also drawing attention. Wen et al. (2003: 848) summarize Wilson's work as showing the benefits of economic heterogeneity for urban communities:

In his [Wilson's] model, the prevalence of middle/upper-income people positively correlates with the material and social resources necessary to sustain basic institutions in urban neighborhoods like the family, churches, schools, voluntary organizations, and informal service programs. ... These institutions are pillars of local social organization that help to nurture neighborhood solidarity and mobilize informal social control.

In their own study, Wen et al. (2003: 856) find that neighborhood affluence exerts a significant positive influence on health net of other covariates, including neighborhood-level poverty, income inequality, aggregated educational attainment, and lagged levels of neighborhood health. However, Pebley and Sastry (2003) could find no separable, significant effect of neighborhood affluence in their Los Angeles study of children's test scores, given controls for the median level of neighborhood family income, which is a significant positive influence on these scores.

In addition to these perspectives on neighborhood effects, one finds a small literature in demography exploring the links between local services and health outcomes, with a particular focus on how services may either provide a substitute for, or alternatively complement, the beneficial effects of mother's education (e.g., Sastry 1996). Relatively poor urban neighborhoods may not be attractive to private-sector suppliers of health services and contraception (although vendors offer drugs and supplies even in poor neighborhoods). These neighborhoods may also lack the political clout to secure adequate public-sector services. It is not a given that poor neighborhoods will be underserved by the public sector-in some countries these neighborhoods could be targeted for improved service provision. ${ }^{3}$

\section{How strong is the evidence?}

Empirical studies of neighborhood effects in developing-country cities are far from being common. For Rio de Janeiro, Brazil, research by Szwarcwald et al. (2002) examines a type of multilevel model in which infant mortality and adolescent fertility rates at the censustract level are posited to depend on the proportion poor and the dispersion of poverty rates in the larger geographic areas within which tracts are nested. These authors find substantial dispersion in poverty across the tracts of such larger areas, and this variation (or inequality) is empirically separable from the mean areal poverty rate. Their analysis shows that the higher the mean poverty rate in the large areas, and the higher the variance, the higher are both infant mortality and adolescent fertility at the tract level. These findings are suggestive of a link between local socioeconomic inequality and health, if not quite as persuasive as estimates from multilevel models with both individual and areal characteristics. 
As a number of researchers have noted (e.g., Timæus and Lush 1995; Szwarcwald et al. 2002; Åberg Yngwe et al. 2003; Drukker et al. 2003; Wen et al. 2003), multilevel studies have often but not invariably found that neighborhood levels of poverty, income, and related factors exert significant influence when individual-level covariates are controlled. Collinearity between the individual and spatially aggregated measures can make it difficult to distinguish between individual and neighborhood effects. Ginther et al. (2000), using longitudinal data with a rich set of individual, family, and neighborhood variables, caution that neighborhood measures often lose their significance as more family- and individual-level covariates are taken into consideration. Longitudinal studies of these relationships are rare, and randomized intervention studies are rarer still.

\section{What is an urban neighborhood?}

The geographical units for which aggregated data are available - in the United States, these are census tracts, block groups, and the like-have boundaries that need not correspond closely, or indeed at all, with the sociological boundaries of neighborhoods as determined by patterns of social interaction, contagion, and comparison. Furthermore, as noted above, it may be that social networks exert important influences on individual and family behavior, and these network contacts are not necessarily confined to the space of local neighborhoods.

In an early, memorable, and still provocative piece, Wellman and Leighton (1979) emphasize the lack of overlap between social interactions taking place in neighborhoods and those taking place in individual social networks. In their view, social networks encompass and extend well beyond neighborhood, place-based connections. Writing on health and reference group effects, Wen et al. (2003: 845) acknowledge, "It is not clear what spatial level is appropriate to examine this relationship.” For Sweden, Åberg Yngwe et al. (2003) explore an approach whereby socially defined reference groups are constituted on the basis of social class, age, and region, rather than in terms of the local geography.

Even the spatial aspect is problematic. Coulton et al. (1997) and Sastry et al. (2002) emphasize the complexities entailed in delineating geographic boundaries for urban neighborhoods. Coulton et al. (1997) asked residents of Cleveland to depict their local neighborhoods on maps and found that the perceived boundaries often differed substantially from the perimeters of census-based units. There was substantial variation among residents in the spatial extent of their perceived neighborhoods. Despite this variation, when averages of socioeconomic measures (e.g., poverty rates, crime rates, nonmarital fertility) were calculated for the perceived neighborhoods and then compared to figures for the census tracts, the composition of the tracts proved to be similar to that of the units sketched out by local residents. For Cleveland, at least, tract-level data can serve as useful proxies. We are not aware of any other research on this crucial point.

In this paper, as in so much of the literature on neighborhood effects, definitions of neighborhood are forced upon us by the nature of the available data. Demographic and Health Surveys collect data within sampling clusters, and we will refer to these clusters as "neighborhoods." The extent to which DHS sampling clusters represent neighborhoods is, of course, 
open to debate. In the cities of developing countries, such sampling clusters are occasionally as small as a single multiunit apartment building, or they can extend more broadly, though they would seldom be as broad in spatial terms as rural sampling clusters. ${ }^{4}$ Unfortunately, the spatial perimeters of DHS sampling clusters are not documented in any accessible format, and it would be a substantial undertaking to retrieve the relevant maps even for recently fielded surveys. Further substantial effort would be needed to determine the nature of social interactions that take place within and outside these spatial perimeters.

For many reasons, then, it is well beyond the scope of this paper to identify precisely the routes through which neighborhoods influence health. Data far more detailed and extensive than those collected in the DHS would be required for a full accounting. In making a preliminary survey of the data sources at hand, we will offer interpretations of our findings that emphasize one or another of the mechanisms described above, and, in closing, will outline priorities for future research.

\section{Statistical OVerview}

The specifications to be explored here take the form of equation systems in which a given health variable, denoted by $Y$, is the main object of interest. As discussed above, in our application $Y$ will represent one of three measures of health: unmet need for modern contraception; attendance of a doctor, nurse, or trained midwife at childbirth; and children's height for age. The first two of these are binary variables.

For the unmet need and birth attendance models, we write the main structural equation in latent variable form as

$$
Y^{*}=W^{\prime} \theta+f \delta+\epsilon
$$

with the observed dependent variable $Y=1$ if $Y^{*} \geq 0$ and $Y=0$ otherwise. For the children's height variable, which is continuously distributed, we can think of $Y$ as being equivalent to $Y^{*}$. The determinants of $Y^{*}$ include a vector of explanatory variables $W$ and an unobservable factor $f$ that we will take to represent the household's standard of living-more in a moment on when this will be a tenable interpretation. Another unobservable, $\epsilon$, serves as the disturbance term of this structural equation.

We posit a model of the factor $f$ such that $f=X^{\prime} \gamma+u$, the value of $f$ being determined by a set of exogenous variables $X$ and a disturbance $u$. Although $f$ is not itself observed, its probable level is signaled through the values taken by $\left\{Z_{k}\right\}$, a set of $K$ indicator variables. These are binary indicators in our application, and it is conventional to represent them in terms of latent propensities $Z_{k}^{*}$, with $Z_{k}=1$ when $Z_{k}^{*} \geq 0$ and $Z_{k}=0$ otherwise. We write each such propensity as $Z_{k}^{*}=\alpha_{k}+\beta_{k} f+v_{k}$, and, upon substituting for $f$, obtain $K$ latent indicator equations,

$$
\begin{aligned}
& Z_{1}^{*}=\alpha_{1}+X^{\prime} \gamma+u+v_{1} \\
& Z_{2}^{*}=\alpha_{2}+\beta_{2} \cdot X^{\prime} \gamma+\beta_{2} u+v_{2} \\
& \quad \vdots \\
& Z_{K}^{*}=\alpha_{K}+\beta_{K} \cdot X^{\prime} \gamma+\beta_{K} u+v_{K} .
\end{aligned}
$$


In this set of equations, the $\beta_{k}$ parameters show how the unobserved factor $f$ takes expression through each indicator. ${ }^{5}$ Whether $f$ is actually interpretable as a living standards index depends on the signs that are exhibited by these parameters.

The full equation system thus comprises the health equation (1) and equations (2) for the living standards indicators. In setting out the model in this way, with latent factors embedded in structural equations, we follow an approach that has been recommended by several researchers (notably Sahn and Stifel 2000; McDade and Adair 2001; Tandon et al. 2002; Ferguson et al. 2003). Filmer and Pritchett (1999, 2001) have developed an alternative approach based on the method of principal components. Although useful in descriptive analyses and very easy to apply, this method is perhaps best viewed as a data-reduction procedure whose main virtue is the ease with which the researcher can collapse multiple indicators into a single index. The principal components approach is otherwise rather limited-it does not cleanly separate the determinants of living standards from the indicators of living standards, and it lacks a firm theoretical and statistical foundation. As a result, the method is not readily generalizable to structural, multiple-equation models such as ours (Montgomery et al. 2000).

For this paper, we will take a two-step approach to estimating the full system. Assuming that the disturbances to be normally distributed, we estimate the parameters $\alpha, \beta$, and $\gamma$ of the indicator equations (2) by the method of maximum likelihood, as described in Appendix $\mathrm{B}$, using routines that we have written for this purpose. ${ }^{6}$ An estimate $\hat{f}=\mathrm{E}[f \mid X, Z]$ of the factor is derived from these indicator equations alone. The predicted $\hat{f}$ is then inserted into the structural equation (1) just as if it were another observed covariate. Conventional statistical methods are applied to estimate the parameters $\theta$ and $\delta$ of the structural model. ${ }^{7}$

It is important to acknowledge a key point: We assume that the disturbance terms $\left\{\epsilon, u, v_{1}, \ldots, v_{K}\right\}$ are mutually independent. The principal worry is that the $\epsilon$ disturbance of the health equation might be correlated with $u$ or one of the $v_{k}$ disturbances. A correlation involving $\epsilon$ could arise if the propensity to own a given consumer durable (for the $k$-th durable, this propensity involves both $u$ and the disturbance $v_{k}$ ) is somehow linked to the disturbance term $\epsilon$ of the main health equation. When the indicator equations (2) are estimated separately, as in our approach, then the estimator $\hat{\gamma}$ is consistent for $\gamma$, and the $X^{\prime} \hat{\gamma}$ component of $\hat{f}$ is (in the limit) free from contamination. ${ }^{8}$ Hence, one could define $\hat{f}=X^{\prime} \hat{\gamma}$ and proceed without concern for inconsistency in the health equation estimators. However, when $\hat{f}$ is formed by conditioning not only on $X$, but also on the indicators $Z$, then an association of $\hat{f}$ with $\epsilon$ could persist even in the limit. If there is reason to be concerned about this sort of bias, the procedure used to generate $\hat{f}$ must be adjusted. Lacking any compelling reason for suspecting correlation, however, we have not made the adjustments here.

\section{Modeling the living standards factor}

With the living standards factor specified as $f=X^{\prime} \gamma+u$, how should the $X$ variables of this equation be chosen and what relation, if any, should they bear to the $W$ variables that enter the main health equation? How are the $X$ variables, posited as determinants of 
living standards, to be distinguished from the $\left\{Z_{k}\right\}$ variables that serve as indicators of living standards?

As Montgomery et al. (2000) note, there is little consensus in the literature about how best to define and model the living standards measures found in surveys such as those fielded by the DHS program, which lack data on consumption expenditures and incomes. With proper consumption data lacking, we think it reasonable to define the set of living standards indicators $\left\{Z_{k}\right\}$ in terms of the consumer durables and housing-quality items for which data are gathered. Using these indicators, we construct what McDade and Adair (2001) have termed a "relative affluence" measure of living standards. Producer durables - in a rural sample these would include ownership of livestock and land—are deliberately excluded from the $\left\{Z_{k}\right\}$ set, because while they may help determine final consumption, producer durables are not themselves measures of that consumption. They are a means to an end, or, to put it differently, producer durables are better viewed as inputs in household production functions, rather than as measures of the consumption drawn from household production.

By this logic, if producer durable variables were available for the urban samples with which we are concerned, we should include them among the $X$ covariates. Unfortunately, as of this writing the DHS program has not collected data on urban producer durables as such. ${ }^{9}$ To be sure, some publicly provided services can also be viewed as enabling factors, or inputs, into consumption-notably, the provision of electricity - and we have therefore included electricity in the $X$ living standards determinants. Although city size may be only a distant proxy for other factors determining consumption-among them, access to multiple income-earning possibilities and heterogeneous labor and product markets-we include city size with the other $X$ variables.

It is perhaps not unreasonable to liken adult education to a producer durable, education being a type of long-lasting trait that produces a lifetime stream of income and consumption; on these grounds we include the education (and age) of the household head in our specification of the $X$ determinants. In doing so, we are mindful of the "dual roles" played by education in demographic behavior (Montgomery et al. 2000). Education is both a determinant of living standards and a conceptually separable influence on behavior via its links to social confidence, to the ability to process information, and to the breadth and nature of individual social networks. In short, education measures belong with the $W$ variables of the health equations as well as in the set of $X$ variables that act as determinants of living standards. Model identification is not threatened by variables that are common to both $X$ and $W$, but we hope to strengthen the empirical basis for estimation by using the education of the household head as a determinant of living standards and the education of the woman and her spouse as determinants of health. ${ }^{10}$

\section{Living standards at the neighborhood level}

Evidently there are many issues to confront in specifying living standards models at the individual and household level; yet further issues must be confronted in any effort to define neighborhood (cluster) living standards. Our approach is very simple. With estimates 
$\hat{f}_{i c}$ in hand for household $i$ in cluster $c$, we construct a cluster-level measure for household $i$ by averaging $\hat{f}_{j c}$ over all households $j \neq i$ that reside in the cluster, that is,

$$
\hat{f}_{i}^{c}=\frac{1}{n_{c}} \sum_{j \neq i} \hat{f}_{j c},
$$

with $n_{c}$ being the number of households in the cluster less one. In our descriptive work we also construct measures of the proportion of cluster households falling into the lowest and highest quartiles of the urban distribution of living standards.

We are exploring two alternative approaches that are better-justified in econometric terms. In one of these, a cluster-level living standards factor $f_{c}$ is introduced along with the household-level factor $f$, and modeled in terms of cluster-level variables. This two-factor approach can be implemented in much the same way as the one-factor approach, although estimation entails far greater computational difficulties given the number of indicators and the typical number of households per cluster seen in the DHS data we use. An alternative, not quite as well-justified but perhaps acceptable as a compromise, is to enter the cluster-level variables as indicators (or determinants) of a single household-level living standards factor.

\section{Data ANd Model SPecification}

The data drawn upon in this analysis come from 85 surveys fielded in Phases 2-4 of the DHS program. ${ }^{11}$ The survey dates range from 1990 through 2001, and fifty countries in six developing regions are represented. See Table A.1 in Appendix A for a list of these countries and their survey years.

\section{Health measures}

Regional summaries of the distributions for the health variables - unmet need for modern contraception; attendance by a physician, nurse, or trained midwife at delivery; and children's height for age-are presented in Table 1. Here and elsewhere in the paper, we use such regional summaries and averages to set the results in context. It should be noted that the DHS are not strictly representative of any developing region, because in no region have all countries, or even all large countries, participated in the DHS program. In addition, several countries have fielded multiple Demographic and Health Surveys.

The first column of Table 1 shows the percentages of women who have an unmet need for contraception. An unmet need can be said to exist when a woman who is not currently using contraception expresses a desire to prevent or delay further births (Westoff and Pebley 1981; Westoff and Bankole 1995; Casterline and Sinding 2000). Among those women who report that they wish to stop childbearing altogether or delay the next birth-excluding those not at risk of conception (i.e., women who are pregnant, amenorrheic, or not in union) - a woman with an "unmet need" is one who uses no modern contraception.

The second health measure in Table 1 is generated from the DHS maternity histories for all births that occurred in the three years before the survey date. For each such birth, information is gathered on who assisted at the delivery of the child, with the possibilities 
Table 1 Mean values of urban unmet need, birth attendance by a doctor, nurse, or trained midwife, and children's height for age, by region

\begin{tabular}{lccc}
\hline Region & Unmet need $^{\mathrm{a}}$ & All recent births attended & Height for age \\
\hline North Africa & 20.8 & 64.4 & -0.715 \\
Sub-Saharan Africa $^{\mathrm{c}}$ & 48.4 & 60.2 & -1.112 \\
Southeast Asia $^{\mathrm{d}}$ & 21.7 & 65.2 & \\
South and Central Asia & 23.4 & 63.2 & -1.241 \\
West Asia & 17.4 & 83.8 & -0.577 \\
Latin America & 22.8 & 70.4 & -0.885 \\
TOTAL & 35.3 & 64.5 & -1.032 \\
\hline
\end{tabular}

${ }^{\text {a }}$ Expressed in percentages of women at risk of unmet need.

b Expressed in percentages of women with births in the last three years whose deliveries were attended by a doctor, nurse, or trained midwife.

c Expressed in standard deviations from an international reference median, with -1.0 being one standard deviation below that median.

d No DHS in this region have collected information on children's height for age.

including a doctor, nurse, trained midwife, other midwife, traditional birth attendant, and relative. This analysis will focus on the women whose deliveries in the last three years have been attended by a doctor, nurse, or trained midwife. The variable is coded with a " 0 " if one birth was attended but another was not-hence, in the case of multiple births in the three years before the survey, it measures consistent attendance.

The DHS program collects information on the height and weight of each child born in the three years before the survey date. ${ }^{12}$ A child's height for age is thought to be a good proxy measure of health status, reflecting both nutrition and disease history (Montgomery et al. 1997). We will focus on height for age among children who are 3-36 months of age, the lower age cutoff being chosen to minimize the problems of measurement error that are believed to plague estimates for the youngest children. Height for age is standardized by age and sex and is represented in terms of standard deviations from the median of an international reference population.

\section{Explanatory variables}

A small set of variables from the DHS is included to serve as socioeconomic controls. Descriptive statistics for these variables are presented in Appendix A; here we discuss the rationale for including the variables and our approach to coding them. The woman's age is coded in the conventional five-year age groups. The urban context is indicated by a pair of dummy variables for residence in the country's capital or another large city (defined by the DHS as a city with at least 1 million population) and residence in a smaller city (with a population of 50,000-1 million residents). The omitted category for residence is towns, that is, urban places with fewer than 50,000 residents. 
Table 2 Coding of educational attainment for multivariate analyses

\begin{tabular}{|c|c|c|c|c|c|c|}
\hline $\begin{array}{l}\text { Number } \\
\text { of surveys }\end{array}$ & $\begin{array}{l}\text { No } \\
\text { education }\end{array}$ & $\begin{array}{l}\text { Incomplete } \\
\text { primary }\end{array}$ & $\begin{array}{l}\text { Completed } \\
\text { primary }\end{array}$ & $\begin{array}{l}\text { Incomplete } \\
\text { secondary }\end{array}$ & $\begin{array}{l}\text { Completed } \\
\text { secondary }\end{array}$ & Higher \\
\hline 64 & \multicolumn{2}{|c|}{ Base $^{\mathrm{a}}$} & \multicolumn{2}{|c|}{ Group 2} & \multicolumn{2}{|c|}{ Group 3} \\
\hline 13 & \multicolumn{2}{|c|}{ Base $^{\mathrm{a}}$} & \multicolumn{2}{|c|}{ Group 2} & Group 3 & Group 4 \\
\hline 7 & \multicolumn{4}{|c|}{ Base $^{a}$} & Group 2 & Group 3 \\
\hline
\end{tabular}

To devise a consistent classification of educational attainment is difficult. The educational experiences of women and their husbands vary a great deal over the range of regions and countries covered in this analysis. For example, over 80 percent of women have completed secondary schooling or more in Kazakhstan and Uzbekistan, whereas only 8 percent and 1 percent have done so in Mali and Burkina Faso, respectively. No single classification scheme can be imposed upon all countries.

We have chosen to define educational attainment for women and their husbands according to the distribution of attainment within each country. This approach yields three distinct coding schemes, as shown in Table 2. Our aim was to devise a measure with a sizable baseline (omitted) category, with 8 percent of the urban sample taken to be the minimum acceptable size for this category. In the great majority of DHS, the base comprises those with no education or at most incomplete primary school education. For a small minority of surveys, however, mainly from the former Soviet republics, this grouping yielded too small a base category, and the base was expanded to include those who completed primary school or attended, but did not complete, secondary school.

\section{Living standards indicators}

The set of living standards indicators $\left\{Z_{k}\right\}$ includes the consumer durables and housing items shown in Table 3 and Appendix Table A.2. As the appendix table shows, these indicators are available in almost all DHS, although some countries lack one or two of them. Some surveys include additional consumer items (e.g., possession of soap or a cooking stove) but we exclude such measures in the interest of achieving reasonable cross-country comparability.

\section{HOUSEHOLd AND NEIGHBORHOOd LiVING STANDARDS}

Table 4 summarizes the estimated $\hat{\beta}_{k}$ factor loadings produced by the confirmatoryfactor models. As can be seen in the table, these coefficients are almost always positive and statistically significant. This is encouraging, in that it supports the interpretation of the factor as an expression of the household's standard of living. Table 5 presents a summary of the effects of the $X$ covariates. These effects are also very much in line with expectations. The 
Table 3 Percentages of urban households with living standards indicators, by region ${ }^{\mathrm{a}}$

\begin{tabular}{lllllll}
\hline Item & $\begin{array}{l}\text { North } \\
\text { Africa }\end{array}$ & $\begin{array}{l}\text { Sub- } \\
\text { Saharan } \\
\text { Africa }\end{array}$ & $\begin{array}{l}\text { Southeast } \\
\text { Asia }\end{array}$ & $\begin{array}{l}\text { South and } \\
\text { Central Asia }\end{array}$ & $\begin{array}{l}\text { West } \\
\text { Asia }\end{array}$ & $\begin{array}{l}\text { Latin } \\
\text { America }\end{array}$ \\
\hline Consumer durables & & & & & & \\
$\quad$ Car & 17.4 & 12.9 & 12.7 & 24.6 & 28.3 & 16.3 \\
Television & 92.6 & 37.4 & 62.6 & 69.9 & 95.8 & 79.0 \\
Refrigerator & 79.4 & 23.9 & 37.2 & 67.9 & 91.9 & 51.8 \\
Radio & 83.9 & 76.6 & 77.2 & 57.4 & 72.6 & 84.6 \\
Bicycle & 17.6 & 21.0 & 48.9 & 31.7 & 10.8 & 27.4 \\
$\quad$ Motorcycle & 10.3 & 12.6 & 30.5 & 12.9 & 0.1 & 8.9 \\
Housing quality & & & & & & \\
$\quad$ Sleeping rooms & 67.3 & 47.7 & 64.8 & 52.4 & 64.9 & 46.2 \\
Finished floors & 94.7 & 76.9 & 75.8 & 47.3 & 79.7 & 77.2 \\
\hline
\end{tabular}

${ }^{\text {a }}$ Unweighted means, based on households with a woman eligible for the unmet-need analysis, using surveys that gathered data on the indicator.

Table 4 Summary of confirmatory-factor loadings $\left(\hat{\beta}_{k}\right)$ for consumer durables and housing quality ${ }^{\mathrm{a}}$

\begin{tabular}{llll}
\hline Item & Estimated & $\begin{array}{l}\text { Positive and } \\
\text { significant }\end{array}$ & $\begin{array}{l}\text { Negative and } \\
\text { significant }\end{array}$ \\
\hline Consumer durables & & & \\
Television & 71 & 69 & 1 \\
Refrigerator & 76 & 75 & 0 \\
Radio & 83 & 82 & 0 \\
Bicycle & 79 & 75 & 4 \\
Motorcycle & 57 & 54 & 1 \\
Housing quality & & \\
Sleeping rooms & 67 & 65 & 2 \\
Finished floors & 78 & 77 & 0 \\
\hline a The $\beta$ parameter for ownership of a car is not estimated but rather normalized to unity; \\
\multicolumn{2}{l}{ see Appendix B for discussion. }
\end{tabular}


Table 5 Summary of $\hat{\gamma}$, the effects of determinants $X$ on the living standards factor

\begin{tabular}{|c|c|c|c|}
\hline Item & Estimated & $\begin{array}{l}\text { Positive and } \\
\text { significant }\end{array}$ & $\begin{array}{l}\text { Negative and } \\
\text { significant }\end{array}$ \\
\hline \multicolumn{4}{|l|}{ Demographic variables for head } \\
\hline Male & 85 & 74 & 11 \\
\hline Age & 85 & 85 & 0 \\
\hline Age squared ${ }^{\mathrm{a}}$ & 85 & 0 & 85 \\
\hline \multicolumn{4}{|l|}{ Head's education ${ }^{\mathrm{b}}$} \\
\hline Completed primary or incomplete secondary & 76 & 76 & 0 \\
\hline Completed secondary or higher & 60 & 60 & 0 \\
\hline Completed secondary & 19 & 19 & 0 \\
\hline Higher & 20 & 20 & 0 \\
\hline Unknown & 12 & 12 & 0 \\
\hline \multicolumn{4}{|l|}{ Other } \\
\hline Household has electricity & 61 & 61 & 0 \\
\hline Residence in small city & 71 & 60 & 11 \\
\hline Residence in capital city & 82 & 74 & 7 \\
\hline
\end{tabular}

provision of electricity is positively associated with living standards, as would be anticipated given its role as a key input. The education of the household head is strongly and positively associated with living standards, and, consistent with age profiles of productivity, we find that living standards increase with the head's age up to about age 60 , and decrease thereafter. Citysize variables show weaker effects overall, but the estimates indicate that living standards are generally higher in small and large cities relative to levels found in towns, the smallest urban areas. Evidently there is good statistical support for the notion that the proxy variables collected in the DHS are interpretable as indicators of the household's otherwise unobservable standard of living.

We now examine the relationship between living standards indexes estimated at the household level and aggregated indexes computed for the other households residing in the sampling cluster. Recall that the approach is to estimate confirmatory-factor scores $\hat{f}_{i c}$ for each household $i$ in urban sampling cluster $c$ in a given DHS dataset. The sampling cluster averages are computed by separating out the score for each household $i$ and calculating a mean for the other households in the cluster. We also examine the proportion of households in the cluster that fall into the lowest quartile of urban factor scores overall and the proportion falling in the uppermost quartile, again without reference to the $i$-th household. These proportions are described in what follows as the cluster proportions "poor" and "affluent," with poverty and affluence being defined in relative terms. 
Figure 2 Distribution of sampling clusters by percentages of relatively poor and relatively affluent households, averages over all DHS.

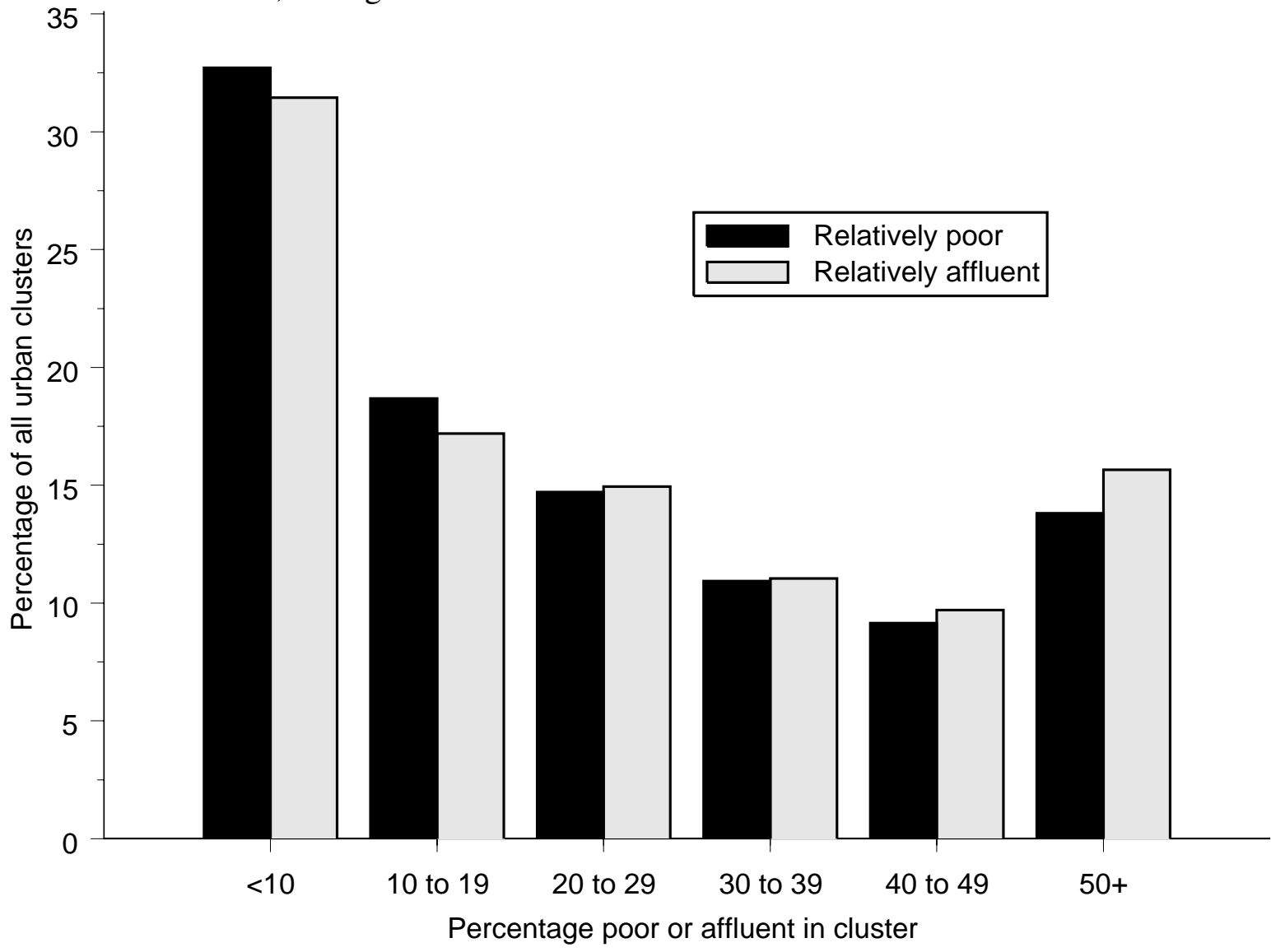

In considering the DHS sampling clusters, we might ask first whether there is evidence that relative poverty and affluence are indeed spatially concentrated. It is reasonable to expect that if 25 percent of urban households overall are poor, in examining a set of sampling clusters we are likely to find some clusters with very high concentrations of poverty and others with very few poor households. Likewise, we might well expect to observe a high spatial concentration of affluence.

Although these are reasonable expectations, the DHS results provide something less than resounding support for them. We see a greater degree of heterogeneity in cluster composition than might have been anticipated. We document this heterogeneity in several ways. Consider Figure 2, which presents the distributions of DHS sampling clusters by the cluster proportion of relative poverty and relative affluence. (Region-specific results, not shown, are very similar to the averages shown here.) In about one-third of urban clusters, fewer than 10 percent of households are poor. Likewise, in about the same percentage of clusters, fewer than 10 percent of households are relatively affluent (that is, in the upper quartile of all urban households). These two left-most bars are suggestive of some spatial concentration of 
poverty and affluence. However, as we consider the full range of the distributions, we see less evidence of extreme spatial concentration. Relatively few clusters are more than half poor or half affluent. ${ }^{13}$

Figures 3 and 4, which refer to all surveys in our analysis, may further clarify matters. In the first of these figures, we characterize the neighbors of poor households. If poor households were indeed generally surrounded by other poor households-as in the images of slums and shantytowns that are invoked in so many discussions of urban poverty-then we would expect to find that their neighbors are predominantly poor. As the figure shows, this is far from being the case. In Latin America, the average poor household lives in a neighborhood in which about 44 percent of its neighbors are poor. To be sure, this is well above the percentage of poor in the urban population as a whole ( 25 percent by our definition of poverty), but it leaves substantial room for neighbors who are in the 25th-75th percentiles of the living standards distribution (in Latin America, this "middle" group accounts for about 45 percent of a poor household's neighbors) and even for neighbors who are affluent, those who are in the top-most quartile of the urban distribution. A poor Latin American household has, on average, about one neighboring household in ten that is affluent.

Figure 4 depicts the neighbors of these affluent households. Again, as expected, slightly more of the neighbors are themselves affluent than in the urban population at large, and affluent households have somewhat fewer poor neighbors (who make up about 20 percent of the neighbors of affluent families). But a household's affluence is not strongly predictive of its neighborhood composition - these are minor departures from the 25th and 75th percentile benchmarks. The spatial concentration of affluence is less clearly evident than would be anticipated given the images of extreme social-spatial polarization that appear so often in the literature.

Table 6 depicts the central tendencies and heterogeneities in terms of correlations between the living standards factor score for a household on the one hand, and a set of clusterlevel measures of living standards on the other. (Recall that the household's own score is removed from the cluster-level measures.) Considering the correlation between the household's factor score and the mean within the cluster, we find the expected positive correlation in the first column of Table 6. Although positive, these correlations are not especially high, the highest being only 0.60 in the surveys from South and Central Asia. The correlations of household living standards scores with the cluster proportions poor and better off (shown in the last two columns of the table) are likewise in the expected directions but modest in size.

In summary, having taken the estimated factor score to be a measure of the standard of living, and having examined the internal composition of clusters in this dimension, we find some support for the hypothesis of spatial concentration of poverty and affluence, but not as much support as we had expected to find. Two cautions are in order. First, there can be no presumption that households inhabiting the same local space will interact, or even serve as relevant points of comparison. The Latin American literature is especially instructive on nonspatial forms of exclusion and segregation (e.g., Caldeira 1999, 2000). Second, as we 
Figure 3 Who are the neighbors of the urban poor?

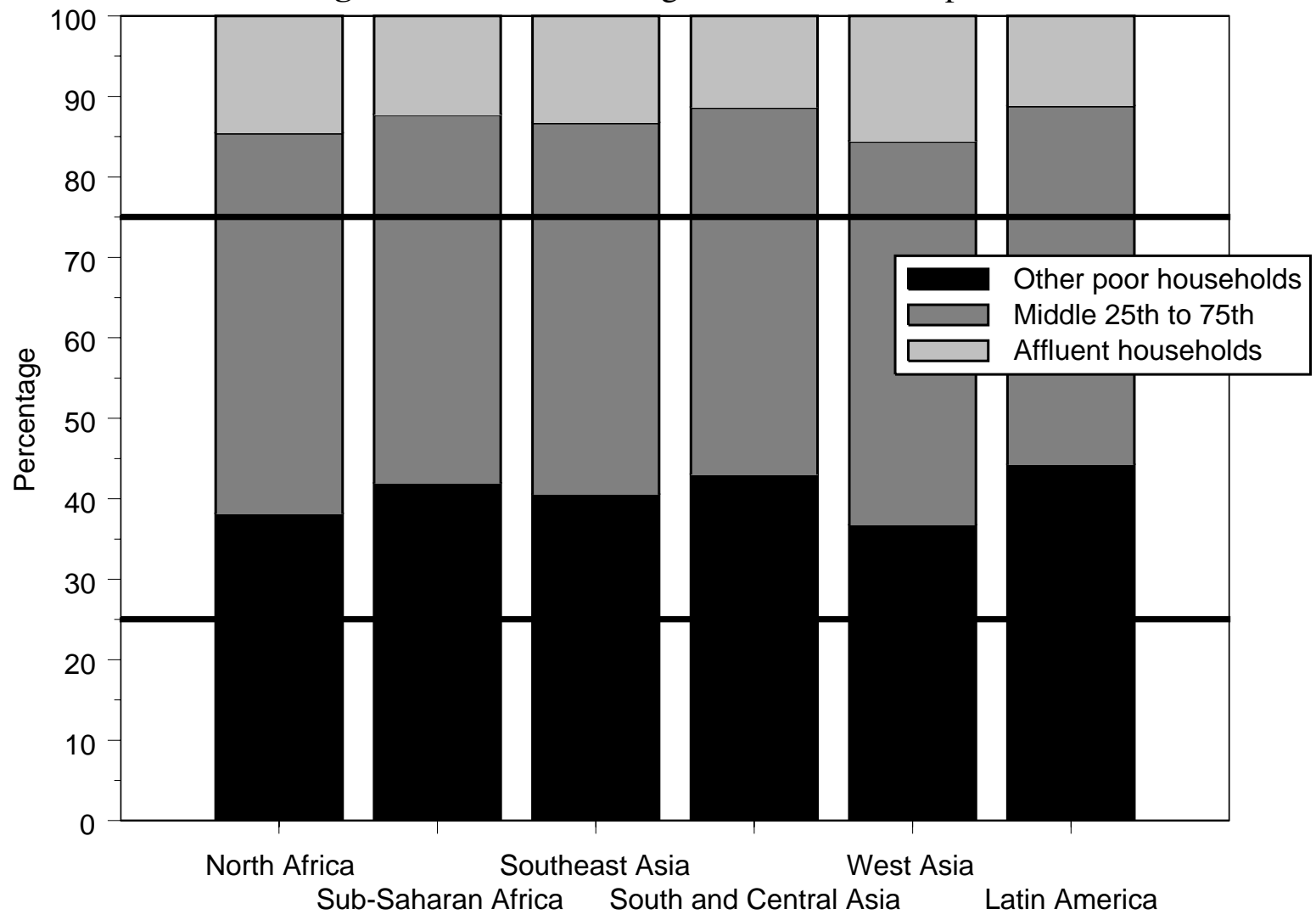

Figure 4 Who are the neighbors of the urban affluent?

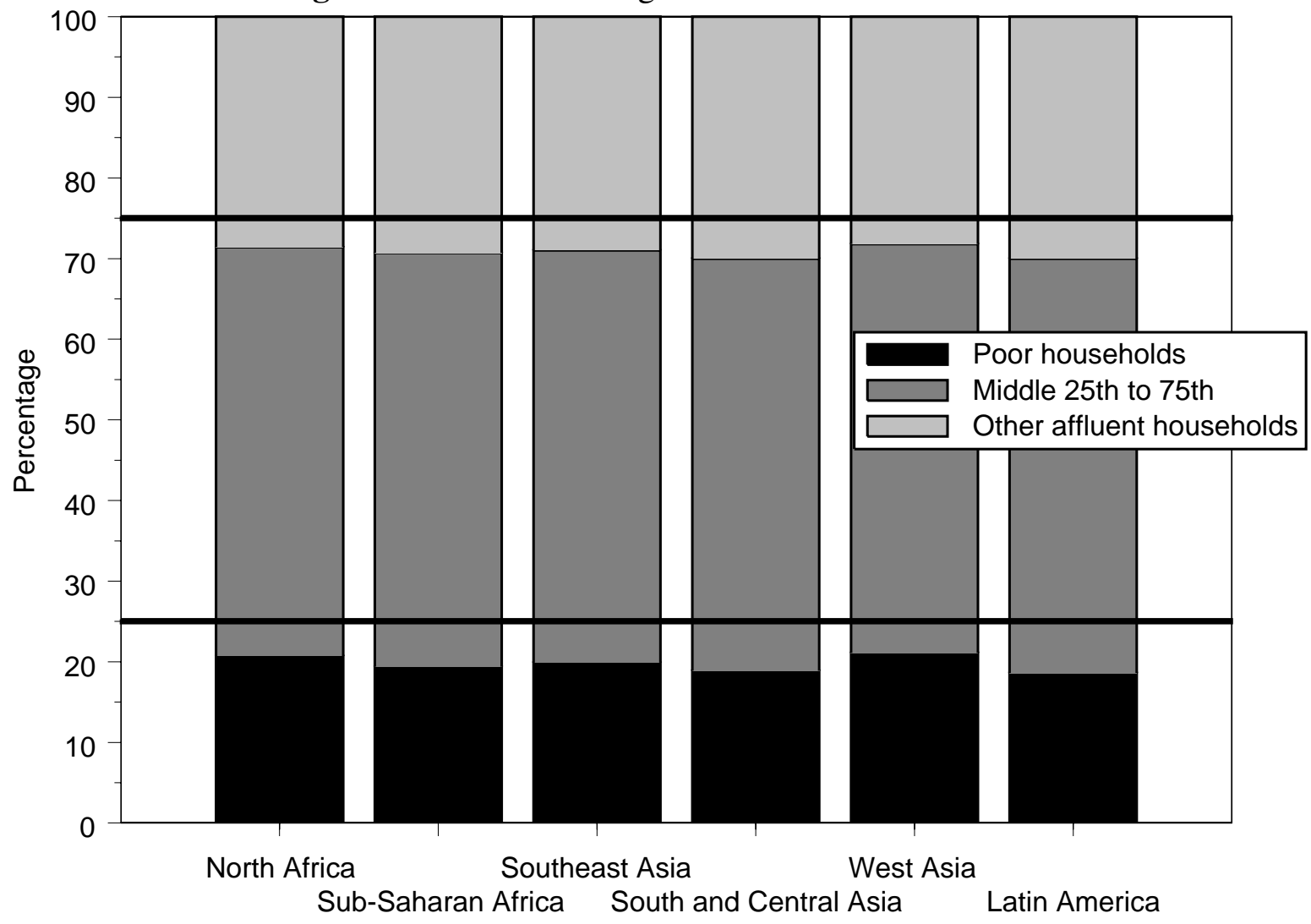


Table 6 Correlations of household and cluster factor scores, by region

\begin{tabular}{llll}
\hline \multirow{2}{*}{ Region } & \multicolumn{3}{c}{ Correlation of household factor score with } \\
\cline { 2 - 4 } & $\begin{array}{l}\text { Mean of cluster }_{\text {scores }^{\mathrm{a}}} \\
\text { North Africa }\end{array}$ & $\begin{array}{l}\text { Proportion of } \\
\text { cluster poor }\end{array}$ & $\begin{array}{l}\text { Proportion of } \\
\text { cluster affluent }\end{array}$ \\
\hline Sub-Saharan Africa & 0.50 & -0.45 & 0.43 \\
Southeast Asia & 0.56 & -0.48 & 0.51 \\
South and Central Asia & 0.53 & -0.49 & 0.46 \\
West Asia & 0.60 & -0.53 & 0.54 \\
Latin America & 0.47 & -0.41 & 0.41 \\
\hline
\end{tabular}

a Household's own score omitted from the calculation.

have already noted, sampling clusters are not the same thing as neighborhoods, and little if anything is known of their correspondence in DHS sampling designs. ${ }^{14}$

\section{Unmet Need, Birth AtTendance, And Height for Age}

In the multivariate empirical work reported below, we began by examining measures of the lower and upper quartiles of the factor score distributions, focusing on the households that we have termed relatively poor and relatively affluent and on the corresponding cluster proportions. To date, however, we have not uncovered empirical evidence suggesting that these measures add insight beyond what can be gleaned from models with individual factor scores and cluster mean scores. (Pebley and Sastry [2003] also found it difficult to isolate the effects of poverty and affluence from the effect of neighborhood medians in their study of Los Angeles neighborhoods.) Although further work needs to be done on specifications involving relative poverty and affluence, the models to which we now turn are specified in simpler terms.

The models of unmet need and birth attendance are based on probit regressions for the $i$-th household in sampling cluster $c$, which can be expressed as

$$
\operatorname{Pr}\left(Y_{i c}=1 \mid W_{i c}, \hat{f}_{i c}, \hat{f}_{i}^{c}\right)=\Phi\left(W_{i c}^{\prime} \theta+\hat{f}_{i c} \delta+\hat{f}_{i}^{c} \delta_{c}\right)
$$

where $\Phi$ is the standard normal cumulative distribution function, $W_{i c}$ denotes the set of explanatory variables measured at the household level, $\hat{f}_{i c}$ is the estimated factor score for the household, and $\hat{f}_{i}^{c}$ is the average of these scores over all except the $i$-th household in the cluster. The model of children's height for age is a simple regression model; the explanatory variables include those used for unmet need and birth attendance, and for this model we add indicators of the child's sex, age, and the square of age (recall that these children are no older than 36 months). Robust standard errors are employed throughout.

To distill a great number of coefficient estimates into a few readily interpretable quantities, we summarize them in the following way. For each health outcome variable, we limit 
discussion to the estimated effects of the household and cluster factor scores, making comments only in passing on the estimates for other explanatory variables. We describe how often the factor score coefficients attain statistical significance and how often they are both significant and of the expected sign.

We then illustrate the size of the living standards effect in two ways. Consider the unmet need analysis. To summarize the effects of living standards, we calculate the predicted probability that woman $i$ has an unmet need given her $W_{i c}$ covariates and given a factor score $\hat{f}_{i c}$ that we fix at the value for the 25 th percentile of the urban factor score distribution (i.e., the distribution across all urban households in the survey in question). We construct another predicted probability using the same $W_{i c}$ covariates but with the factor score now set to the value corresponding to the 75 th percentile of the score distribution. (The 25th and 75th percentile points are chosen to be suggestive of a relatively poor and a relatively affluent urban household.) We average the predictions $P_{i, 25}$ and $P_{i, 75}$ over the urban estimation sample used in the survey, thereby obtaining two averages, $P_{25}$ and $P_{75}$. The difference between these, $P_{25}-P_{75}$, is one illustration of the size of the factor score's effect in a given DHS sample. We term this the "absolute difference" in the predicted probabilities of unmet need. In the tables that follow, the absolute difference is expressed in terms of percentage points. A second illustrative device is constructed by dividing the absolute difference by the average level of unmet need in the survey's urban sample, giving $\left(P_{25}-P_{75}\right) / \bar{P}$. We describe this second measure as the "difference relative to the mean." It may convey a sense of the proportional effect of the factor score, and we report these relative differences in terms of percentages.

A similar approach is taken in describing the effects of the cluster-level factor score means, although in this case the 25 th and 75 th percentile points are taken from the distribution of cluster mean scores across clusters. Because cluster means are means, they tend to have more concentrated distributions than the individual household scores, and we take this into account in choosing values to represent relatively poor and relatively better-off clusters.

\section{Models with household factors only}

Tables 7-9 summarize the results from models using the household factor scores together with the set of socioeconomic controls. There is an impressive consistency in the findings across the three measures of health. First, the factor scores are generally statistically significant and take the expected sign in each of the health equations. As can be seen in the second columns of these tables, the household score is negative and significant in 64 of the 84 DHS in the unmet need analysis (Table 7), is positive and significant in 63 of the 76 surveys where birth attendance is examined (Table 8), and is positive and significant in 49 of 73 surveys analyzing children's height for age (Table 9). The proportions of significant findings are strikingly similar to those for mother's education, as can be seen in the notes to the tables.

The substantive implications of the household scores are summarized in the remaining columns of these tables. We first focus on the absolute effect, comparing predicted values for households at the 25th percentile of the score distribution (the "poor" households) with those at the 75th percentile (the "affluent"), and then examine the effects relative to the mean of 


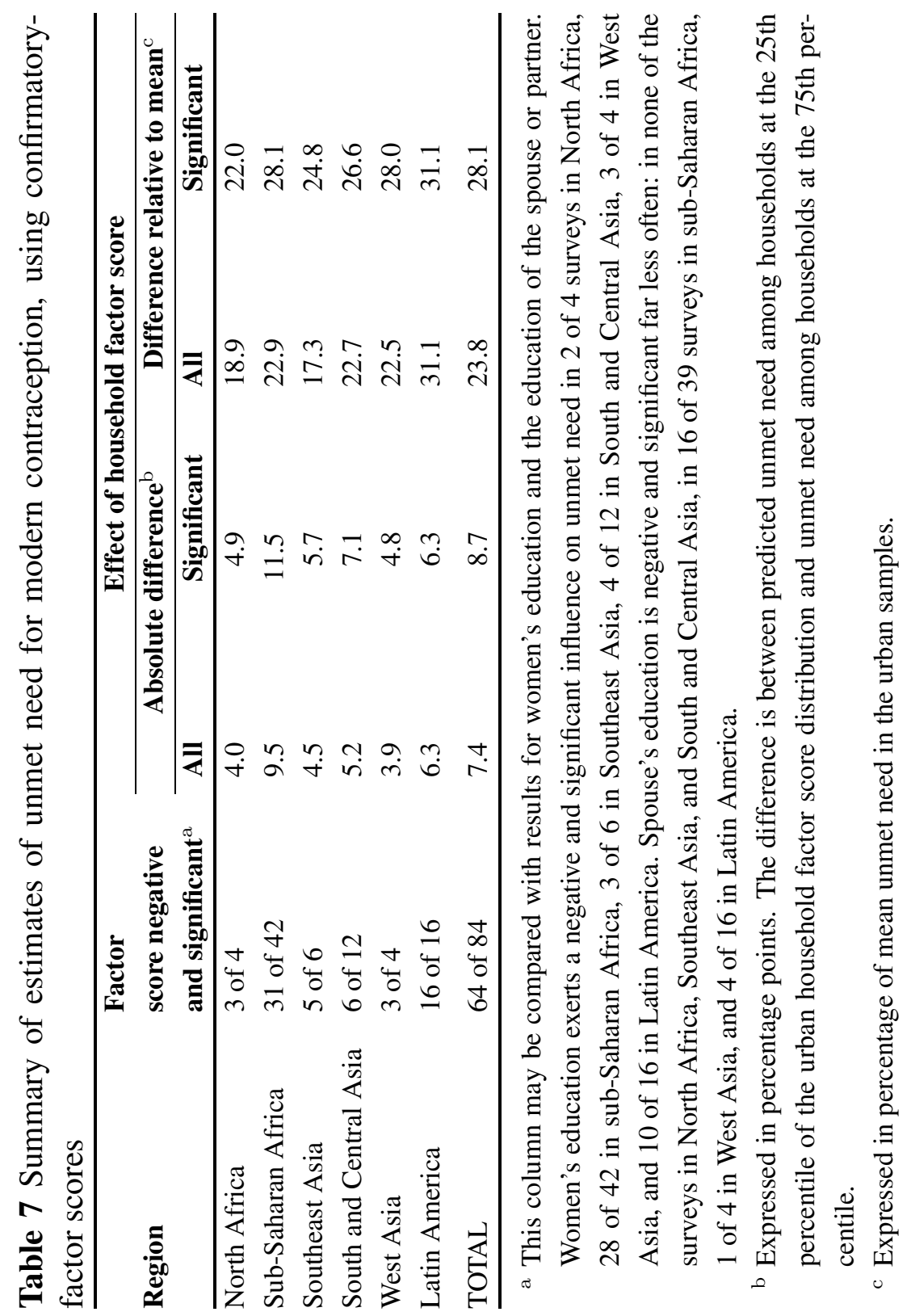




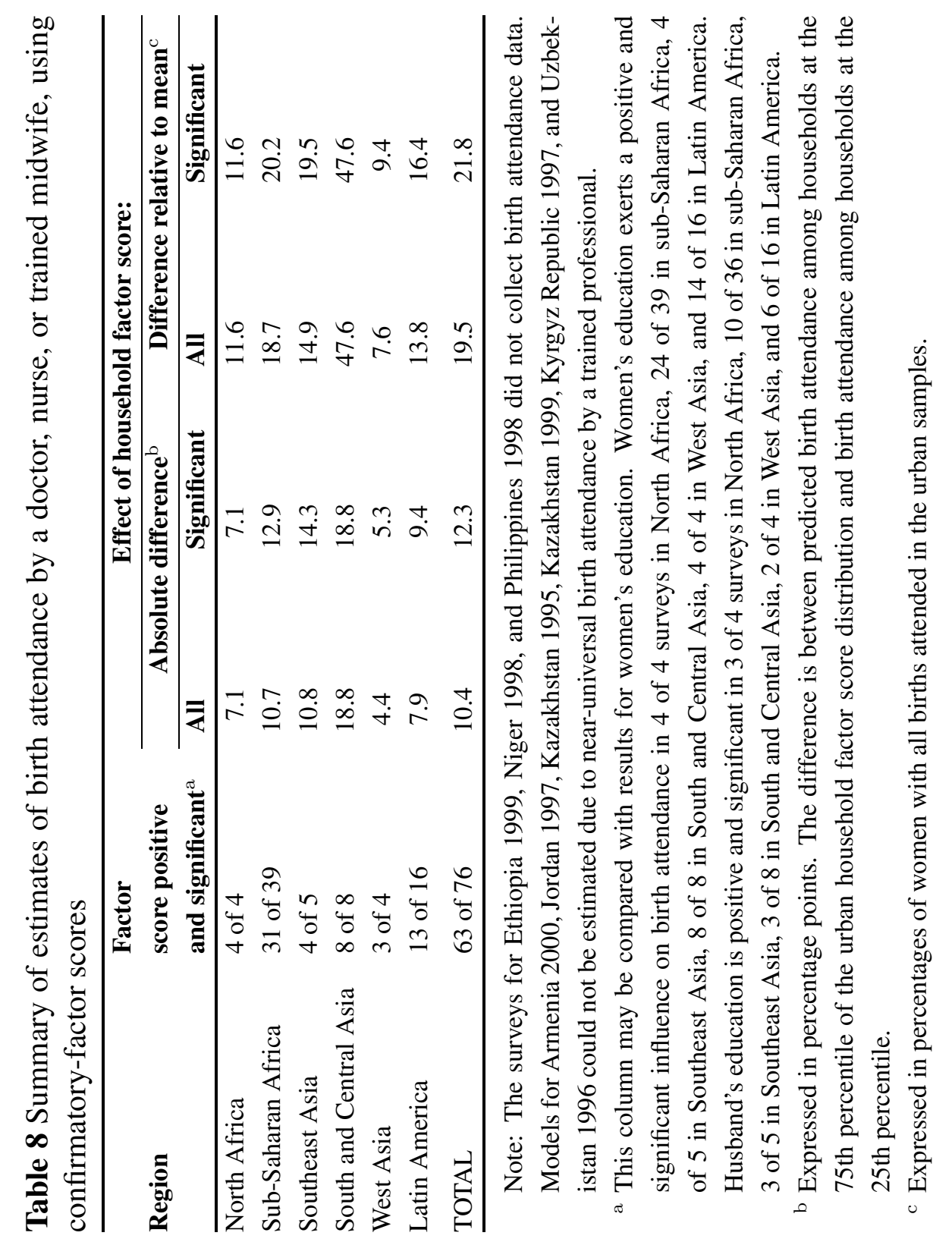




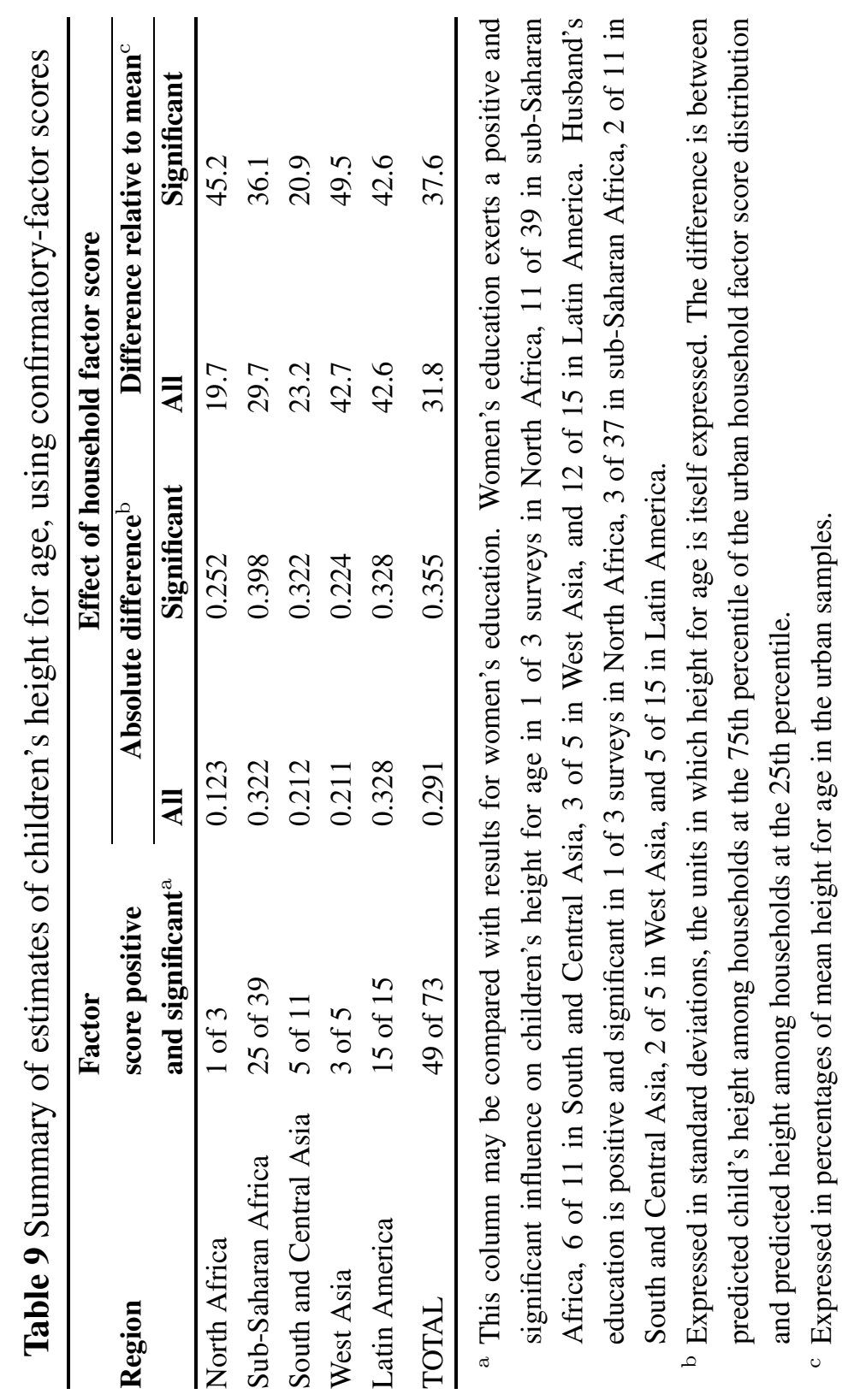


each dependent variable. The estimated effects are reported for all surveys, and separately for the surveys in which a statistically significant coefficient was found. For the unmet need analysis (Table 7), we see that the average difference in the unmet need percentage implied by this comparison is 7.4 percentage points in the full sample (see the "Total" row) and 8.7 percentage points in the sample with significant results. Among the regions, the largest absolute effects are found in sub-Saharan Africa and Latin America. When these absolute effects are translated into relative terms (the last two columns of the table), we see that an absolute difference of 6.3 points in the Latin American results is equivalent to 31.1 percent of the mean level of unmet need. The relative effects of the household factor for the other regions are generally smaller than this but are still of considerable substantive importance.

Much the same story emerges from the analyses of birth attendance and children's height for age, which are summarized in Tables 8 and 9. The estimated influence of the household living standards factor on birth attendance is large in terms of the percentage point differences between poor and affluent households, and these absolute differences imply differences relative to mean attendance that range from 7.6 percent in West Asia to 47.6 percent for the significant cases of South and Central Asia. In the height-for-age models (Table 9), where absolute effects are expressed in terms of standard deviations from the reference median, the implied difference between an affluent and a poor household is on the order of 0.291 standard deviations of children's height. These differences are quite large in relative terms, especially in Latin America. Clearly, even within urban sectors that are generally better supplied with transport options and health services, a household's standard of living can make a considerable difference in its health.

\section{Models with both household and cluster factor scores}

To weigh the evidence for "neighborhood effects," we now add the cluster means of the household factor scores to the models, retaining all other covariates and the household's own factor score. The results are summarized in Tables 10-12. We first describe the number of surveys in which a significant effect is found for the cluster variable, and also check the significance of the household scores to determine whether separate household and cluster effects can really be discerned. We then describe the influence of the cluster scores, comparing predicted values at the 25 th percentile of the cluster score distribution (the "poor" clusters) with those at the 75th percentile ("affluent" clusters).

In general, the cluster-level factors are not statistically significant as often as the individual household factors, and in fact the significance of the household factors is little affected by the inclusion of the cluster measures. (Each table includes a column indicating how often the household factors are significant; as can be seen, in relatively few cases does the inclusion of a cluster-level average remove statistical significance from the household factor.) For unmet need, the cluster mean score is negative and significant in 16 of the 84 surveys examined (Table 10); is positive and significant in 53 of the 76 cases for birth attendance (Table 11); and is positive and significant in 22 of 73 cases for children's height for age (Table 12). Although smaller in the typical case, the absolute effects of the cluster scores still exert a reasonably 


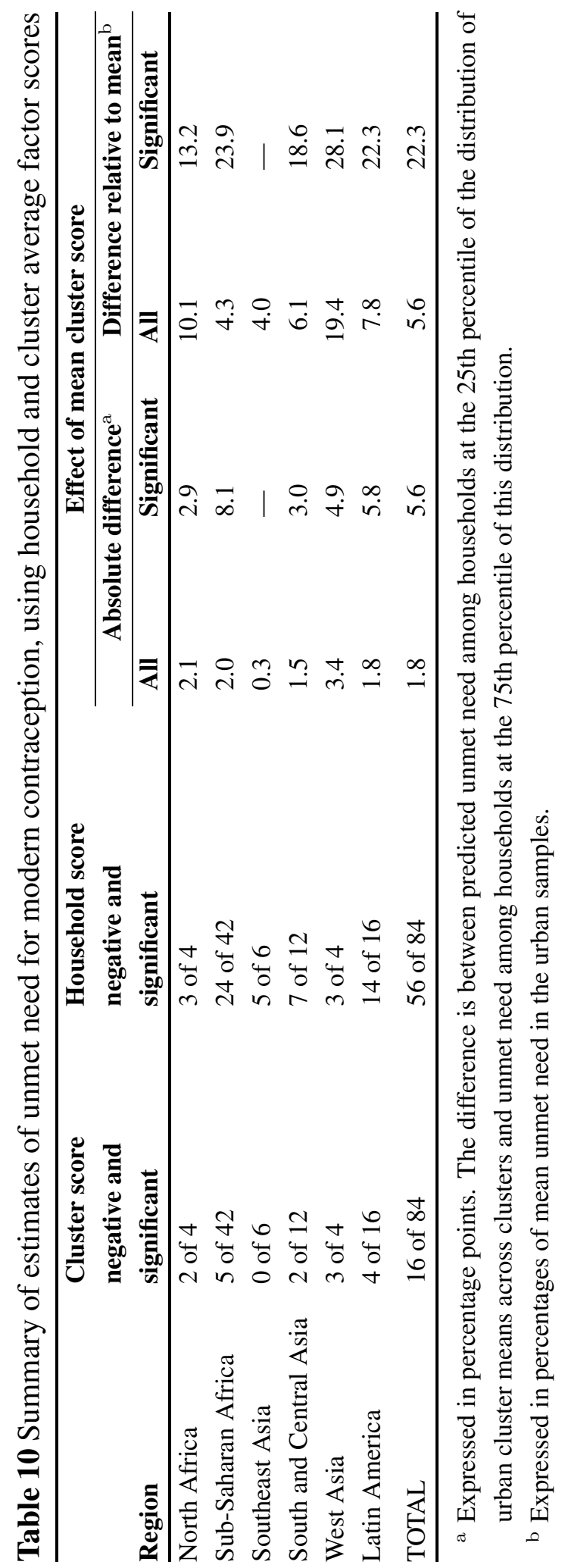




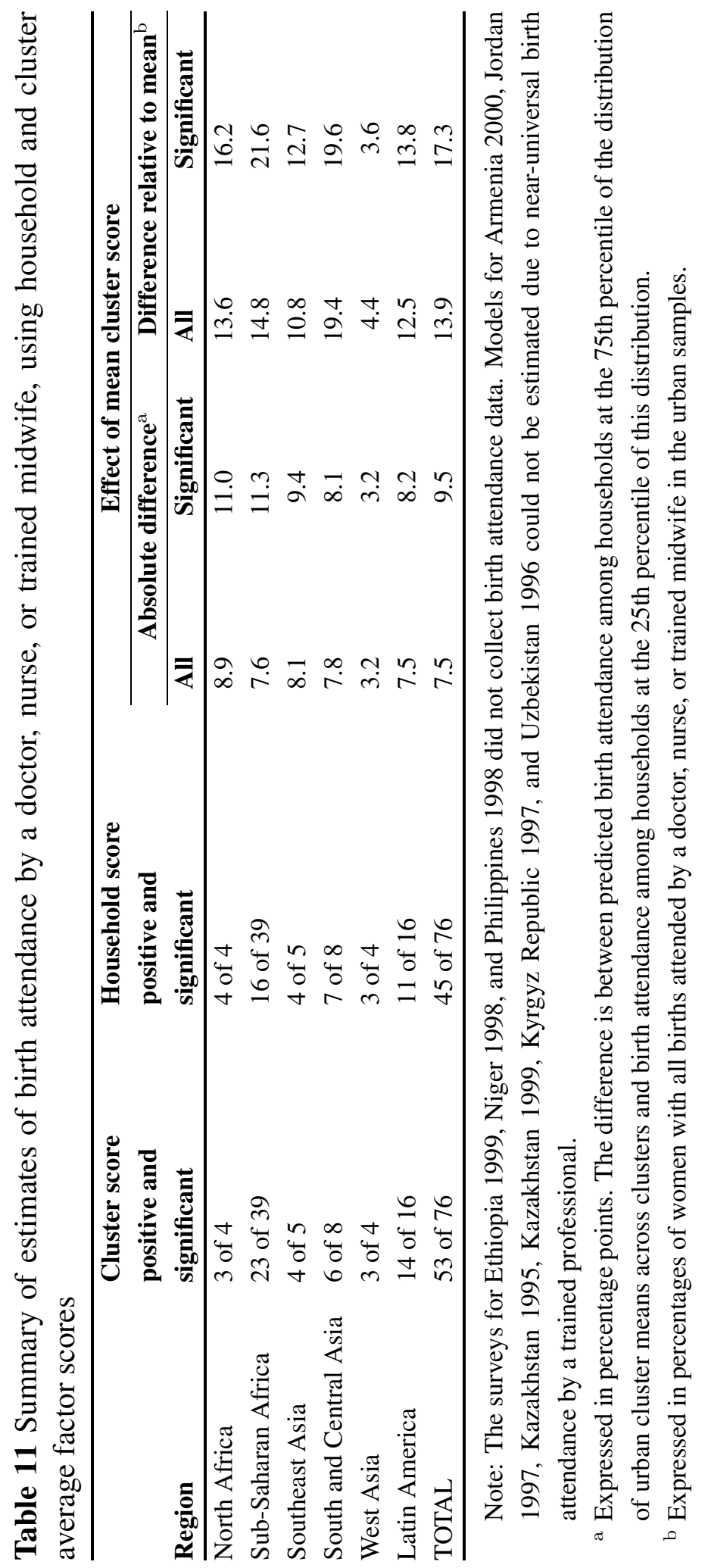




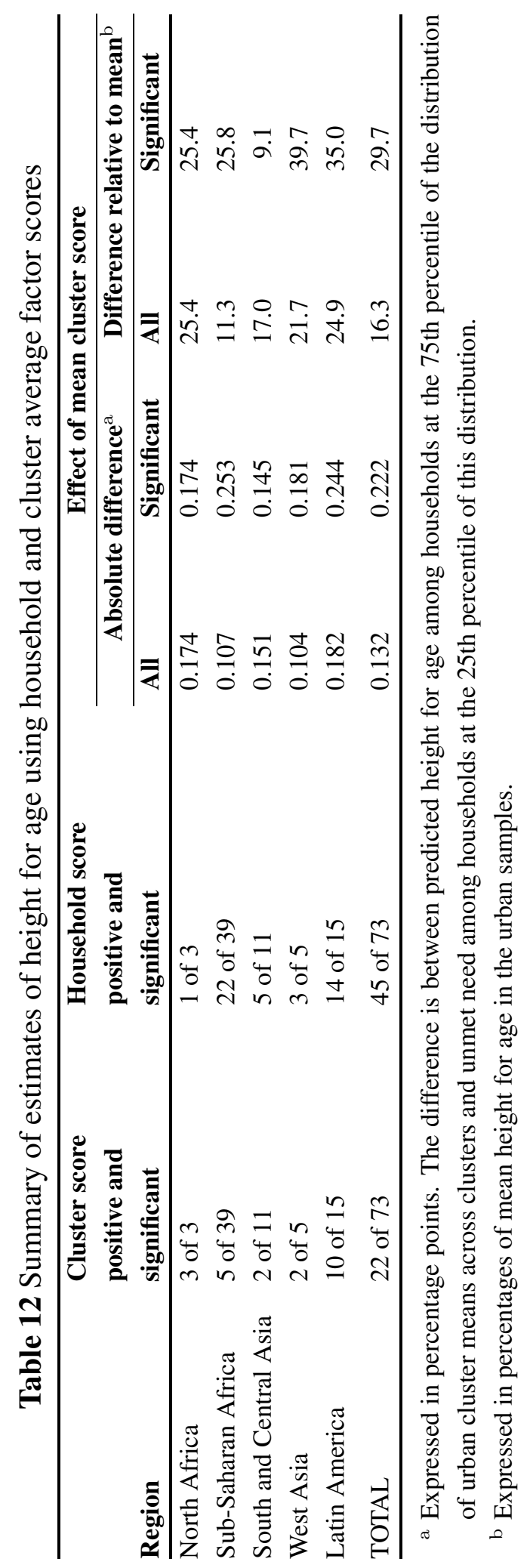


strong influence on the three measures of health, with the effects being most striking in the case of birth attendance. If the absolute effects are translated into relative terms, they are seen to be of substantive importance.

How does the general pattern of findings square with the theories of neighborhood effects that were outlined earlier? The three main pathways of influence that have been mentioned involve health externalities associated with communicable diseases; social externalities stemming from localized patterns of interaction, information flow, and the like; and the effects of local service provision.

We had expected to find the clearest expression of neighborhood effects in the children's height analyses, because here is where one would think health externalities and the risks of contagion in poor neighborhoods would be most apparent. There are numerous significant and relatively large effects seen in height for age (Table 12), especially in Latin America, but on the whole the cluster measure attains significance in under one-third of all surveys. It may be that cluster means of living standards scores are simply too many steps removed from the epidemiological mechanisms that produce within-neighborhood contagion. Direct measures of health in the cluster (e.g., percentages of children with recent fevers or diarrhea) might better isolate this particular pathway of influence. Also, note that the models do not include access to piped water and improved sanitation, and these measures of services need to be examined before any strong conclusions can be drawn.

In our view, the results linking neighborhood living standards to birth attendance are surprisingly strong. We do not think that contagion effects in the narrow epidemiological sense can be involved here. But neighborhood patterns of social interaction and information exchange could make a crucial difference in how city residents assess the risks of childbirth, whether they feel comfortable with modern medical professionals, and the extent to which they are motivated to pay for modern services. (Household abilities to pay are indicated in the strong effects of the household-level factor scores.) These are examples touching on the social epidemiology of health and health-seeking behavior. Our results for urban communities may thus parallel what Pebley et al. (1996) found for rural Guatemalan villages: strong associations among community residents in birth attendance that may stem from shared norms and views about appropriate care during childbirth.

There may be other explanations for the patterns we have found. As noted earlier, relatively poor urban neighborhoods may not be well equipped with private-sector health services, and even public-sector clinics and hospitals may be located elsewhere if governments make little effort to target services to the poor. These possible pathways cannot be examined in great depth with DHS data, but we have not yet exploited all of the DHS measures available. For example, many DHS have fielded community modules even in urban areas, and these may shed light on the local availability of health services.

\section{Conclusions}

This paper can be read as a progress report on a far-from-completed research agenda. We have found strong evidence that household living standards, as measured by confirmatory- 
factor scores, exert substantial influence on the unmet need for modern contraception, birth attendance, and children's height for age. The effects are generally statistically significant (not always, to be sure, but the fraction significant is strikingly similar to that for women's education) and these effects are clearly of substantive importance. Our measures of living standards at the level of the cluster attained statistical significance less often, but when they were significant, these cluster effects were also found to be of substantive importance. To judge from our results, there is good reason to believe that both dimensions of living standards influence urban health in developing countries. It seems that the health of poor households can depend not only on their own standards of living, but also on the economic composition of their neighborhoods.

As we think about the meaning of these empirical results, it is worth remembering just how crude some of the key measures are. The concept of a living standard is measured only imperfectly by a few simple indicators $\left\{Z_{k}\right\}$ and determinants $X$. The concept of neighborhood is also very imperfectly measured by the use of DHS sampling clusters. We hope that the mismatches between neighborhood (a social construct) and sampling clusters (a statistical device) are not so great as to threaten the conclusions of this research-but we know of no direct evidence on this point. The notion of living standards at the neighborhood level is measured through simple averages of the household-level factors, and, as we have noted, more could be done to strengthen this aspect of the econometric models.

Our conceptualization of neighborhood composition is simplistic-more attention could be paid to neighborhood social composition, as reflected in the percentages of local residents who are educated, for example (Coleman 1988; Kaufman et al. 2002; Kravdal 2003). Theories of urban social and environmental interaction and externalities (Panel on Urban Population Dynamics 2003) indicate a need for the collection of social network and spatial data that lie well outside the scope of the DHS program, and that will require new sorts of surveys to be fielded in the cities of developing countries. Much could be learned, we believe, through application to these cities of the conceptual and measurement tools being applied to poor urban communities in the United States. We would like to think that when relatively strong results emerge from models with rather weak measures, as they have here, more tightly focused investigations may well turn up even stronger findings.

As our descriptive analyses have shown, the neighborhoods of poor urban households often contain considerable percentages of nonpoor households, and even appreciable percentages of the affluent, with some one in ten of a poor household's neighbors typically belonging to the upper quartile of the urban distribution. This neighborhood heterogeneity in living standards has not been much remarked upon in demographic analyses of developing-country cities. To the extent that heterogeneity brings social, economic, and political resources within the reach of the poor, it may suggest greater potential for neighborhood-based interventions than some might have thought.

To appreciate this potential, consider a health intervention that aims to improve the lives of the urban poor. Should such a program be situated in a neighborhood where nearly all residents are poor and health needs are greatest? Or is there reason to consider mixed- 
income sites as well? Mixed-income communities may be able to supply more volunteers for community-based organizing activities, and may also possess a stronger base of local associations. The middle- and upper-income residents of such communities could conceivably serve as "bridges" to politicians, government agencies, and sources of outside funding and expertise. For these reasons, neighborhood social and economic heterogeneity could well amplify the positive effects of health interventions. In theory, at least, programs set in such heterogeneous neighborhoods could yield more benefits for the poor than those located in uniformly poor neighborhoods. But there are also risks in situating health interventions in mixed-income communities. Program benefits could be siphoned off by upper-income residents, and it could prove difficult to sustain community motivation for activities for the poor when better-off residents have the means to purchase health care. These are obviously difficult and situation-specific issues. If the heterogeneity that we have documented is characteristic of the neighborhoods of the developing-country urban poor, it will present both challenges and opportunities for health programs and policies. 


\section{APPENDiX A. FurTher DESCRIPTION OF DHS SURVEYS AND DATA}

Table A.1 Demographic and Health Surveys, Phases 2-4

\begin{tabular}{|c|c|c|c|}
\hline$\overline{\text { Region or Country }}$ & Survey year & Region or Country & Survey year \\
\hline North Africa & & \multicolumn{2}{|l|}{ Southeast Asia } \\
\hline Egypt & $1992,1995,2000$ & Indonesia & 1991, 1994, 1997 \\
\hline Morocco & 1992 & Philippines & 1993, 1998 \\
\hline Sub-Saharan Africa & & Vietnam & 1997 \\
\hline Benin & 1996 & \multicolumn{2}{|c|}{ South, Central, West Asia } \\
\hline Burkina Faso & 1992,1998 & Armenia & 2000 \\
\hline Cameroon & 1991,1998 & Bangladesh & 1993, 1996, 1999 \\
\hline Central African Republic & 1994 & India & 1992, 1998 \\
\hline Chad & 1996 & Jordan & 1997 \\
\hline Comoros & 1996 & Kazakhstan & 1995,1999 \\
\hline Côte d'Ivoire & 1994, 1998 & Kyrgyz Republic & 1997 \\
\hline Ethiopia & 1999 & Nepal & 1996, 2000 \\
\hline Ghana & 1993,1998 & Pakistan & 1990 \\
\hline Guinea & 1999 & Turkey & 1993, 1998 \\
\hline Kenya & 1993, 1998 & Uzbekistan & 1996 \\
\hline Madagascar & 1992,1997 & Yemen & 1991 \\
\hline Malawi & 1992,2000 & Latin America & \\
\hline Mali & 1995,2001 & Bolivia & 1993,1998 \\
\hline Mozambique & 1997 & Brazil & 1996 \\
\hline Namibia & 1992 & Colombia & $1990,1995,2000$ \\
\hline Niger & 1992,1998 & Dominican Republic & 1991,1996 \\
\hline Nigeria & 1999 & Guatemala & 1995, 1999 \\
\hline Rwanda & 1992,2000 & Haiti & 1994,2000 \\
\hline Senegal & 1992,1997 & Nicaragua & 1997 \\
\hline South Africa & 1998 & Peru & $1991,1996,2000$ \\
\hline Tanzania & 1991, 1996, 1999 & & \\
\hline Togo & 1998 & & \\
\hline Uganda & 1995,2000 & & \\
\hline Zambia & 1992,1996 & & \\
\hline Zimbabwe & 1994, 1999 & & \\
\hline
\end{tabular}


Table A.2 Number of DHS with consumer durables and housing quality variables available, by region

\begin{tabular}{lllllll}
\hline & $\begin{array}{l}\text { North } \\
\text { Africa }\end{array}$ & $\begin{array}{l}\text { Sub- } \\
\text { Saharan } \\
\text { Africa }\end{array}$ & $\begin{array}{l}\text { Southeast } \\
\text { Asia }\end{array}$ & $\begin{array}{l}\text { South and } \\
\text { Central } \\
\text { Asia }\end{array}$ & West Asia & $\begin{array}{l}\text { Latin } \\
\text { America }\end{array}$ \\
$\begin{array}{l}\text { Surveys with consumer durables } \\
\text { Refrigerator }\end{array}$ & 4 & 39 & 5 & 7 & 4 & 16 \\
$\begin{array}{l}\text { Television } \\
\text { Radio }\end{array}$ & 4 & 40 & 6 & 12 & 4 & 16 \\
Bicycle & 4 & 42 & 5 & 12 & 3 & 16 \\
$\begin{array}{l}\text { Motorcycle } \\
\text { Car }\end{array}$ & 4 & 42 & 6 & 12 & 2 & 12 \\
Surveys with housing quality & 2 & 41 & 5 & 8 & 2 & 12 \\
$\quad$ Number of sleeping & 3 & 41 & 6 & 6 & 4 & 13 \\
rooms & 3 & 36 & 3 & 6 & 3 & 15 \\
Finished floors & 4 & 42 & 6 & 9 & 4 & 16 \\
Number of DHS & 4 & 42 & 6 & 12 & 4 & 16 \\
\hline
\end{tabular}

Table A.3 Descriptive statistics on resident status (percent)

\begin{tabular}{lll}
\hline Region & Capital or large city & Small city \\
\hline North Africa & 35.6 & 40.7 \\
Sub-Saharan Africa & 43.6 & 30.8 \\
Southeast Asia & 30.2 & 35.2 \\
South and Central Asia & 34.3 & 30.0 \\
West Asia & 40.6 & 30.0 \\
Latin America & 40.4 & 31.8 \\
\hline
\end{tabular}




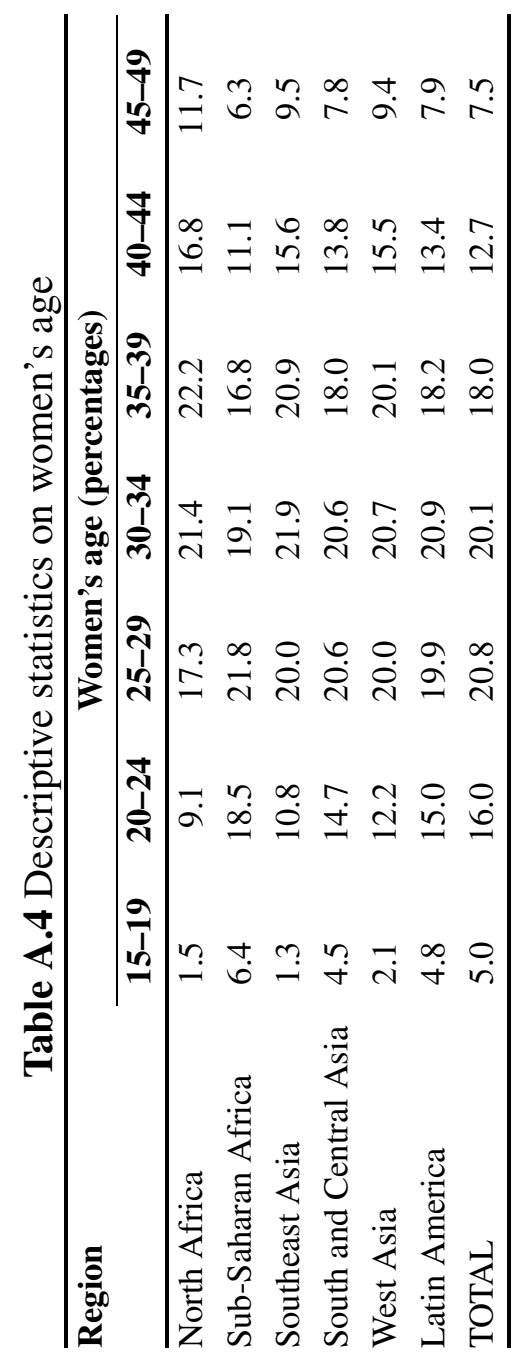




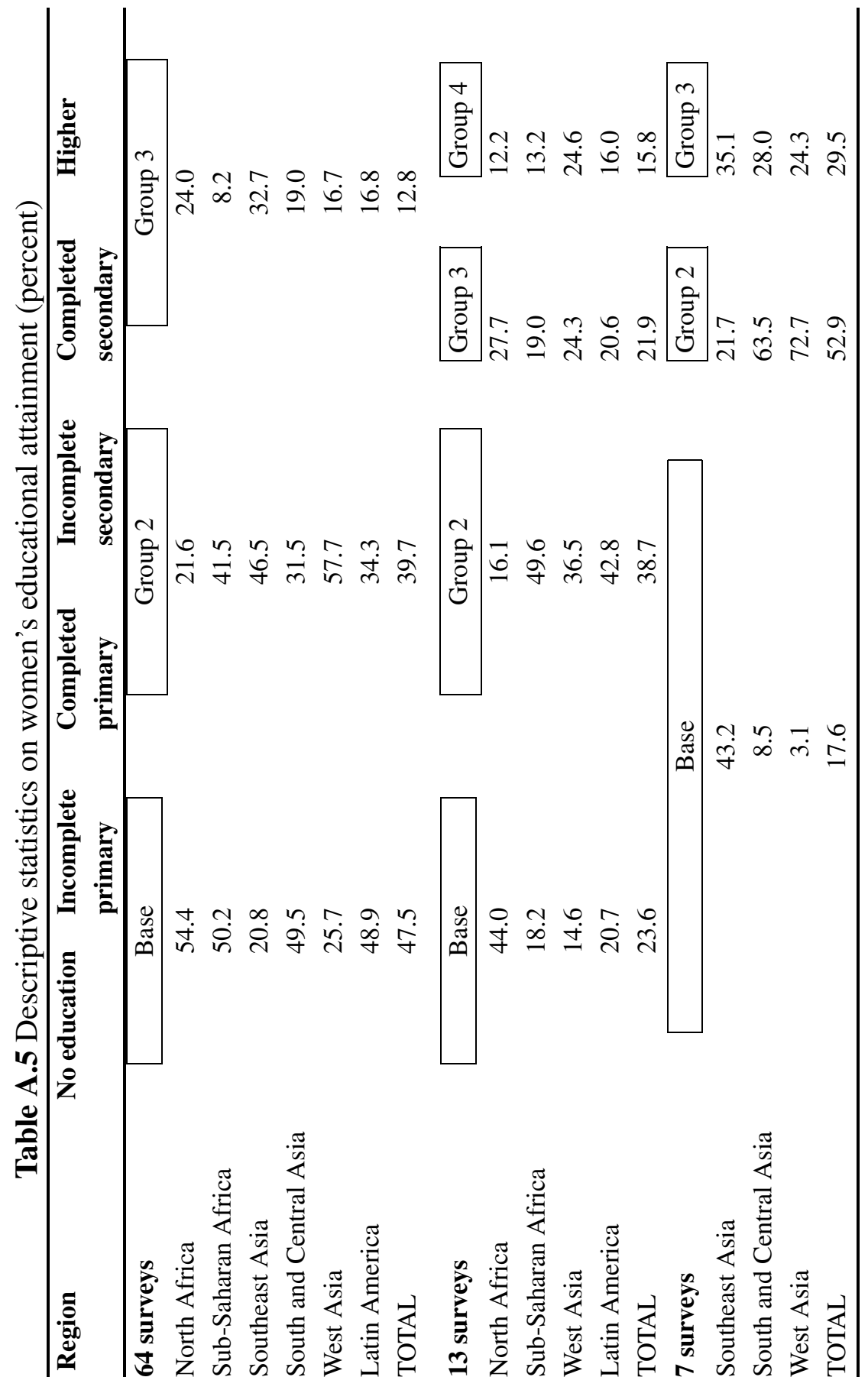




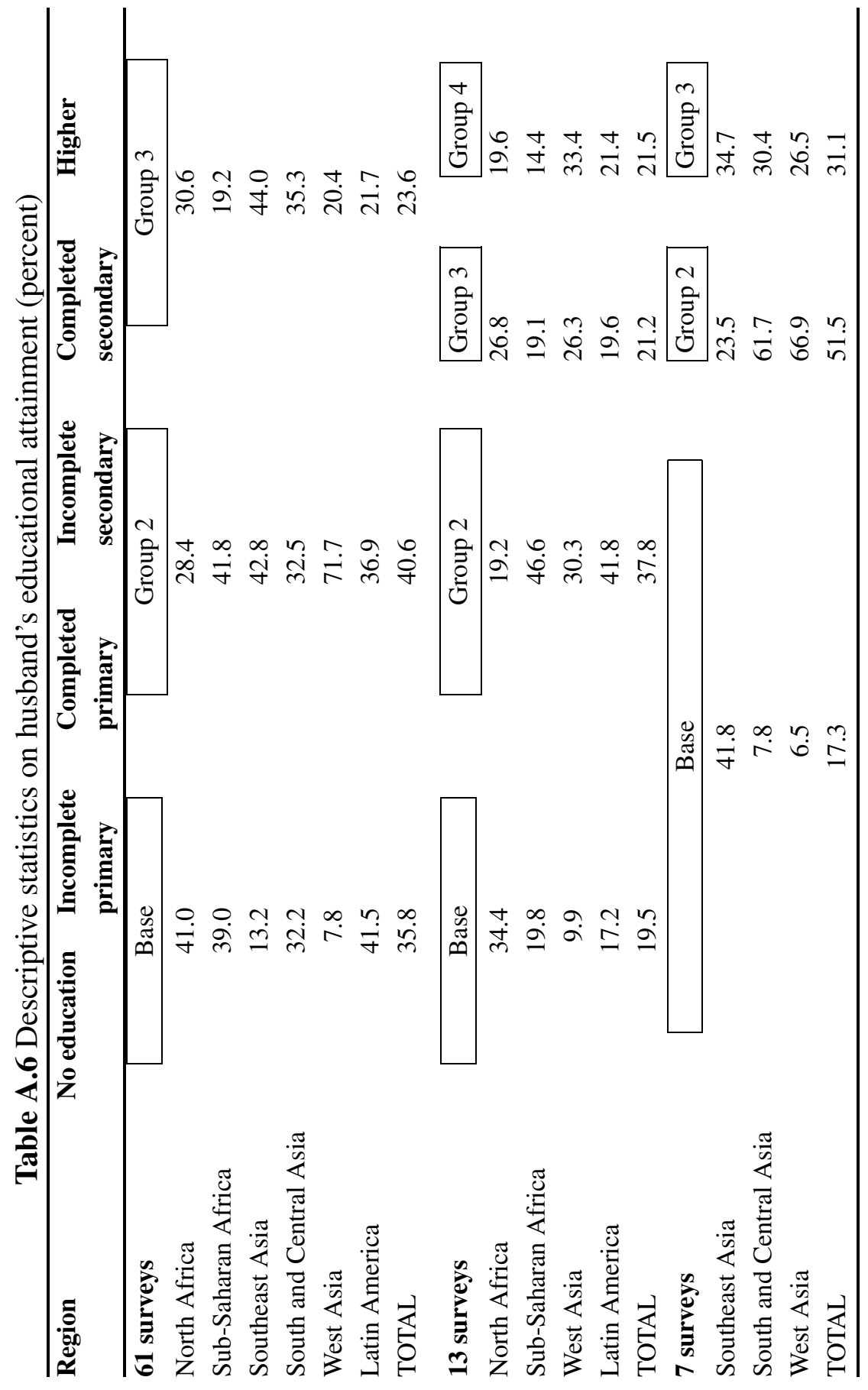




\section{Appendix B. Estimating One-Factor Models With Multiple Binary Indi- CATORS}

The application for which this appendix is written involves using a set of binary consumer durables measures - termed "indicators" here and in the text—to shed light on an otherwise unobserved construct, the household "standard of living." Many other applications of the basic ideas come to mind. For instance, one can think of multiple indicators of health, each of which reflects an individual's underlying "healthiness."

In our application, every household $i$ in the sample provides a vector $Z_{i}$ containing $K$ observed binary indicators, with each of these being denoted by $Z_{i k}$. To begin, we describe a multiple-indicator model in which the indicators are expressions of an unobserved factor $f_{i}=u_{i}$, which we take to represent household $i$ 's standard of living. Many of the estimation details are discussed in this simple context, as are the procedures used to estimate $u_{i}$ given the observed values of the indicators. The last section of the appendix sets out an expanded model in which $f_{i}=X_{i}^{\prime} \gamma+u_{i}$, allowing covariates $X_{i}$ to play a role in determining the standard of living. The expanded model is the so-called MIMIC specification, this being an acronym for "multiple indicator, multiple cause." Throughout the discussion, the indicators are assumed to be dichotomous rather than continuously valued.

\section{The multiple indicator model}

In this specification each element of the indicator vector $Z_{i}$ is assumed to depend on an unobserved factor $f_{i}=u_{i}$. Consider $Z_{i k}$, one of the $K$ indicators. This observed indicator is linked to its latent counterpart $Z_{i k}^{*}$ via two equations, the first being

$$
\begin{aligned}
Z_{i k}^{*} & =\alpha_{k}+\beta_{k} f_{i}+v_{i k} \\
& =\alpha_{k}+\beta_{k} u_{i}+v_{i k} .
\end{aligned}
$$

In equation (B-1), $\alpha_{k}$ is a cut-point parameter and $\beta_{k}$ is a coefficient indicating how the unobserved factor $u_{i}$ takes expression through the $k$-th indicator. The latent variable $Z_{i k}^{*}$ is then linked with its observed counterpart $Z_{i k}$ through the second relation

$$
Z_{i k}= \begin{cases}1 & \text { if } Z_{i k}^{*}>0 \\ -1 & \text { if } Z_{i k}^{*} \leq 0\end{cases}
$$

Although unconventional, this $\{1,-1\}$ coding scheme simplifies both the analytics and the programming.

In what follows, we will indicate the dependence of the vector $Z_{i}$ on $u_{i}$ using the notation $P_{i}\left(u_{i}\right)$, with $P_{i}$ being the joint probability distribution associated with $Z_{i}$ conditional

on the (unknown) value of $u_{i}$. The unconditional probability associated with $Z_{i}$ is derived by "integrating out" the unobserved random factor. We will assume that the factor $u_{i}$ is normally distributed with mean zero and variance $\rho$. Given this, the unconditional probability is expressed by the integral

$$
\int_{-\infty}^{\infty}(2 \pi)^{-1 / 2} \rho^{-1 / 2} e^{-\frac{1}{2 \rho} u_{i}^{2}} P_{i}\left(u_{i}\right) d u_{i} .
$$


Unfortunately, the integral is not available in a closed form, and numerical approximation methods are required to evaluate it.

\section{Background on quadrature}

The method of Gaussian quadrature is often applied when one desires a good approximation to an integral of the type

$$
\int_{-\infty}^{\infty} e^{-\epsilon^{2}} P(\epsilon) d \epsilon
$$

where the function $P(\epsilon)>0$ and the integral in question cannot be represented in a closed form. (Note that, for the moment, the $i$ subscript has been suppressed.) The quadrature method approximates this integral by a weighted summation over a preselected number of quadrature points. The method is explained in illuminating detail by Press et al. (1992, 1996), who provide additional references as well as programming subroutines that calculate the quadrature points and the weights associated with them.

To put equation (B-2) in this form, we need only make a change of variables

$$
\epsilon=\frac{u}{\sqrt{2} \rho^{1 / 2}},
$$

with $\rho^{1 / 2}$ being the standard deviation of $u$. The transformation implies $u^{2}=2 \rho \epsilon^{2}$ and

$$
\frac{d u}{d \epsilon}=\sqrt{2} \rho^{1 / 2}
$$

Upon making the change of variables, we obtain

$$
\pi^{-1 / 2} \int e^{-\epsilon^{2}} P\left(\sqrt{2} \rho^{1 / 2} \epsilon\right) d \epsilon,
$$

which is in the required form apart from the constant $\pi^{-1 / 2}$. The quadrature method approximates the integral by the sum

$$
\sum_{j=1}^{n_{q}} w_{j} P\left(\sqrt{2} \rho^{1 / 2} e_{j}\right),
$$

whose index $j$ ranges over $n_{q}>1$ quadrature points. The quadrature points $e_{j}$ are symmetric about zero, as are the weights $w_{j}$ with which they are associated. The number of points $n_{q}$ is under the control of the researcher, but the quality of the approximation generally improves as the number of points increases.

\section{Maximum likelihood estimation: General approach}

Let $L_{i}^{*}$ represent the contribution made by household $i$ to the sample likelihood function and let $L_{i}$ be the contribution to the sample log-likelihood. The contribution depends on covariates specific to household $i$ and on a set of parameters $\theta$, one of which is the variance 
$\rho$ of the random factor. (The other parameters will be discussed shortly.) To display these dependencies more explicitly than we have thus far, we write

$$
L_{i}^{*}=\pi^{-1 / 2} \sum_{j=1}^{n_{q}} w_{j} P_{i}\left(\theta_{0}, \sqrt{2} \rho^{1 / 2} e_{j}\right) .
$$

In this notation, $\theta_{0}$ contains all unknown parameters save $\rho$, and we let the full set of parameters be denoted by $\theta=\left(\theta_{0}, \rho\right)^{\prime}$.

Estimation of the parameters $\theta$ proceeds by maximizing the full log-likelihood function $L=\sum_{i} \ln L_{i}^{*}=\sum_{i} L_{i}$. A key step is to derive the score vector, which is the vector of derivatives $\partial L / \partial \theta$, with

$$
\frac{\partial L}{\partial \theta}=\sum_{i} \frac{\partial L_{i}}{\partial \theta} .
$$

Note that household $i$ 's contribution to the score is

$$
\frac{\partial L_{i}}{\partial \theta}=\frac{\sum_{j} w_{j} \frac{\partial P_{i j}}{\partial \theta}}{\sum_{j} w_{j} P_{i j}} .
$$

It will prove helpful to re-express this derivative in the form

$$
\frac{\partial L_{i}}{\partial \theta}=\frac{\sum_{j} w_{j} P_{i j} \frac{\partial \ln P_{i j}}{\partial \theta}}{\sum_{j} w_{j} P_{i j}},
$$

because the derivatives of $\ln P_{i j}$ with respect to $\theta$ are generally similar to their counterparts in models without random factors.

\section{Estimation of the model}

For convenience, we repeat here the latent variable equation (B-1),

$$
Z_{i k}^{*}=\alpha_{k}+\beta_{k} u_{i}+v_{i k}
$$

In constructing probability expressions for the observed indicators $Z_{i k}$, we assume that the disturbance term $v_{i k}$ of equation (B-1) is normally distributed with mean zero and variance $\sigma_{v_{k}}^{2}$. We take $u_{i}$ and $v_{i k}$ to be independent of each other for all $i$ and $k$, and assume that the elements of $\left\{v_{i k}, k=1, \ldots, K\right\}$ are mutually independent. Hence, although the various $Z_{i k}^{*}$ are intercorrelated, their correlations stem from a common dependence on the $u_{i}$ factor. Conditional on $u_{i}$, the latent variables $Z_{i k}^{*}$ are independent, as are their observable $Z_{i k}$ counterparts.

In probit structures such as these, the sizes of the disturbance variances are not identified, and some normalization rule must be imposed. Following in the spirit of Heckman (1981: 129), we choose the rule to be $\beta_{k}^{2} \rho+\sigma_{v_{k}}^{2}=1$. This is a convenient rule to apply if one begins with $\hat{\alpha}_{k}$ estimates from standard probit models, as those estimates are based on an 
assumed disturbance variance of unity. Note that under the normalization rule, the variance of $v_{i k}$ is $1-\beta_{k}^{2} \rho$. We also define $\beta_{1} \equiv 1$ for reasons to be explained below.

Equation (B-1), which defines the latent indicator $Z_{i k}^{*}$, may now be multiplied through by $r_{k}=\left(1-\beta_{k}^{2} \rho\right)^{-1 / 2}$ to give a result expressed in the usual probit form. We can see that

$$
r_{k} Z_{i k}^{*}=r_{k}\left(\alpha_{k}+\beta_{k} u_{i}\right)+r_{k} v_{i k}
$$

is in the desired form as $r_{k} v_{i k}$ is standard normal. The probability associated with the observed dependent variable $Z_{i k}$, conditional on the random factor $u_{i}$, is then

$$
\operatorname{Pr}\left(Z_{i k}=z_{i k} \mid u_{i}\right)=\Phi\left(z_{i k} r_{k} \cdot\left(\alpha_{k}+\beta_{k} u_{i}\right)\right),
$$

where $\Phi$ is the standard normal cumulative distribution function, and we have made use of our unconventional $\{1,-1\}$ coding scheme for $Z_{i k}$ and the symmetry of the normal distribution. The product of such probabilities over all indicators for household $i$ is

$$
P\left(u_{i}\right)=\prod_{k=1}^{K} \Phi\left(z_{i k} r_{k} \cdot\left(\alpha_{k}+\beta_{k} u_{i}\right)\right) .
$$

Recall that to integrate out the unobservable random effect $u$, we need the quadrature approximation to an integral of the general form,

$$
\int_{-\infty}^{\infty}(2 \pi)^{-1 / 2} \rho^{-1 / 2} e^{-\frac{1}{2 \rho} u^{2}} P(u) d u
$$

Applying the change of variables and using $n_{q}$ quadrature points, we obtain

$$
L_{i}^{*}=\pi^{-1 / 2} \sum_{j=1}^{n_{q}} w_{j} P_{i}\left(\theta_{0}, \sqrt{2} \rho^{1 / 2} e_{j}\right)=\pi^{-1 / 2} \sum_{j=1}^{n_{q}} w_{j} P_{i j},
$$

in which $\theta_{0}=(\alpha, \beta)^{\prime}$, this being a vector of length $2 K-1$ containing all unknown parameters except for $\rho$, the variance of the factor (recall that $\beta_{1} \equiv 1$ ). When we need to see the roles of the parameters more clearly, we write out the expression for $P_{i j}$ in full, as

$$
P_{i j}=P_{i}\left(\theta_{0}, \sqrt{2} \rho^{1 / 2} e_{j}\right)=\prod_{k=1}^{K} \Phi\left(z_{i k} r_{k} \cdot\left(\alpha_{k}+\beta_{k} \sqrt{2} \rho^{1 / 2} e_{j}\right)\right) .
$$

Below we will refer to this expression as $P_{i j}(\theta)$, a notation in which the vector $\theta=(\alpha, \beta, \rho)^{\prime}$, of length $2 K$, contains all of the model's unknown parameters.

\section{The scores}

Recall that household $i$ 's contribution to the full score vector is

$$
\frac{\partial L_{i}}{\partial \theta}=\frac{\sum_{j} w_{j} P_{i j} \frac{\partial \ln P_{i j}}{\partial \theta}}{\sum_{j} w_{j} P_{i j}} .
$$


Now, $\ln P_{i j}(\theta)$ is itself the sum over $k$ of the $\operatorname{logs}$ of the probabilities specific to indicator $k$ :

$$
\ln P_{i j}(\theta)=\sum_{k=1}^{K} \ln \Phi\left(z_{i k} r_{k} \cdot\left(\alpha_{k}+\beta_{k} \sqrt{2} \rho^{1 / 2} e_{j}\right)\right) .
$$

Hence, for the $\alpha$ parameters we take derivatives of equation (B-3) to obtain

$$
\frac{\partial \ln P_{i j}}{\partial \alpha_{k}}=\frac{\phi_{i k, j}}{\Phi_{i k, j}} z_{i k} r_{k},
$$

with $\phi_{i k, j}$ being the derivative of $\Phi_{i k, j}$ with respect to its argument. Both $\phi_{i k, j}$ and $\Phi_{i k, j}$ are evaluated at the point $z_{i k} r_{k} W_{k j}$, with $W_{k j}=\alpha_{k}+\beta_{k} \sqrt{2} \rho^{1 / 2} e_{j}$. Note that the expression involves only parameters specific to the $k$-th indicator.

For the $\beta$ parameters, we face a more complicated derivation because $r_{k}$ depends on $\beta_{k}$. For $k \geq 2$ (again recall that $\beta_{1} \equiv 1$ ), the result is

$$
\frac{\partial \ln P_{i j}}{\partial \beta_{k}}=\frac{\partial \ln P_{i j}}{\partial \alpha_{k}} \cdot\left(W_{k j} r_{k}^{2} \beta_{k} \rho+\sqrt{2} \rho^{1 / 2} e_{j} .\right)
$$

As for the derivative with respect to $\rho$, a parameter that enters all of the indicator equations, if we recall that $r_{k}$ is also a function of $\rho$ we obtain

$$
\frac{\partial \ln P_{i j}}{\partial \rho}=\sum_{k=1}^{K} \frac{\partial \ln P_{i j}}{\partial \alpha_{k}} \cdot \frac{\beta_{k}}{2}\left(W_{k j} r_{k}^{2} \beta_{k}+\sqrt{2} \rho^{-1 / 2} e_{j}\right) .
$$

These results provide all the ingredients needed to estimate the model.

\section{Notes on identification}

In setting out the multiple-indicator model, we have imposed a number of restrictions, and some comment is in order on why these are needed and how the restrictions help to identify the parameters. Note first that the restriction $\beta_{1}=1$ is something more than a trivial normalization. Consider a model with a given set of $\left\{\beta_{k}\right\}$ parameters. Because the unobserved factor $u_{i}$ is symmetrically distributed about zero, given normality, a second model that is observationally equivalent to the first can be constructed by reversing the signs of all of the $\beta_{k}$ parameters while leaving their magnitudes untouched. Fixing $\beta_{1}=1$ eliminates this possibility. However, in choosing to set the first of the $\beta_{k}$ parameters to unity, we are making the assumption that the first indicator $Z_{i 1}$ is known to be positively associated with the unmeasured factor. If there is any doubt about this assumption, another indicator should be used in its place.

A second point to note is that the variances of the composite disturbance terms-by "composite" we mean $u_{i}+v_{i 1}$ for the first indicator and $\beta_{k} u_{i}+v_{i k}$ for the $k$-th-are not identified in latent-variable models with binary indicators. By setting each of the composite variances to unity, we are imposing restrictions that acknowledge this fact. 
Consider, then, a two-indicator model. The unknown parameters of this model are $\alpha_{1}, \alpha_{2}, \beta_{2}$, the factor's variance $\rho$, and the disturbance variances $\sigma_{v_{1}}^{2}$ and $\sigma_{v_{2}}^{2}$, giving a total of six parameters. Two restrictions are imposed via the unit variance assumptions, and this reduces the number of unknowns to four. However, the data at hand provide us with only three quantities that can be calculated: conventional single-equation probit models supply consistent estimates of $\alpha_{1}$ and $\alpha_{2}$, and the covariance between $Z_{i 1}^{*}$ and $Z_{i 2}^{*}$ can be estimated consistently by a bivariate probit. Unless further assumptions can be made, the two-indicator model is underidentified.

Counting up parameters and calculable quantities for a three-indicator model shows that this model is just-identified. After imposing variance restrictions, we are given six parameters to estimate. Three conventional probits identify the $\alpha_{k}$ parameters, and three applications of bivariate probit supply estimates of the three cross-equation covariances. By the same logic, models with four indicators or more are overidentified. Each additional indicator adds a new pair of $\alpha_{k}, \beta_{k}$ parameters to estimate, to be sure, but each indicator also makes available a new set of cross-equation covariances that help in estimating all of the $\beta_{k}$ parameters and the $\rho$ parameter.

If many indicators are available, some of the assumptions made above can be relaxed. For instance, if the model is overidentified given the assumption of zero covariance between disturbance components $v_{i j}$ and $v_{i k}, j \neq k$, then additional parameters can be introduced to allow for a limited number of nonzero covariances.

\section{Numerical optimization issues}

Our experience in estimating these models suggests that on occasion they present numerical difficulties. In particular, we have encountered cases in which one of the normalizing factors $r_{k}=\left(1-\beta_{k}^{2} \rho\right)^{-1 / 2}$ behaves badly as the result of a steady drift upward in its $\beta_{k}$. We have not been able to diagnose the root cause of the problem; fortunately, it is generally easy to correct. To arrest the tendency for one or more of the $\beta_{k}$ to drift upward, we have programmed special checks that are applied during the course of optimization, which temporarily reduce the absolute amount of change permitted in the parameters once such drift is detected. Slowing things down in this way generally allows the optimization to regain its footing and proceed smoothly thereafter. As a further safeguard, we have estimated the models using an initial grid search over $\rho$, estimating all other parameters for each $\rho$ value in the grid. The best estimates $\hat{\alpha}, \hat{\beta}$, and $\hat{\rho}$ emerging from this grid search are presented as starting values to a full maximum likelihood estimation routine.

\section{Estimating the unobserved factor}

Even though the factor $u_{i}$ is unobserved, we can estimate its value from the values of the observed indicators $Z_{i}$ for that observation. The procedure is little more than an application of Bayes' Rule. We seek the conditional expectation

$$
E\left(u_{i} \mid Z_{i}\right)=\int u P\left(u \mid Z_{i}\right) d u
$$


in which the conditional density $P\left(u \mid Z_{i}\right)$ is the density for the factor $u$ given the indicator vector $Z_{i}$ for the $i$-th household. By Bayes' Rule,

$$
P\left(u \mid Z_{i}\right)=\frac{P\left(u, Z_{i}\right)}{P\left(Z_{i}\right)}=\frac{P\left(Z_{i} \mid u\right) \phi(u)}{P\left(Z_{i}\right)}
$$

with $\phi(u)$ being the normal density function for a factor with mean 0 and variance $\rho$. Note that $P\left(Z_{i}\right)$ is the contribution made by observation $i$ to the sample likelihood.

Given realized values $Z_{i}=z_{i}$, the numerator of $P\left(u \mid Z_{i}\right)$, as it is expressed on the right-hand side of equation (B-8), can be written as

$$
\prod_{k=1}^{K} \Phi\left(z_{i k} r_{k} \cdot\left(\alpha_{k}+\beta_{k} u\right)\right) \cdot \phi(u)
$$

and the denominator of equation (B-8) is the integral of (B-9) over $u$.

To calculate the conditional expectation of $u$, we start with the quadrature approximation to $\int u P\left(Z_{i} \mid u\right) \phi(u) d u$, which is

$$
\pi^{-1 / 2} \sum_{j=1}^{n_{q}} w_{j}\left(\sqrt{2} \rho^{1 / 2} e_{j}\right) \cdot \prod_{k=1}^{K} \Phi\left(z_{i k} r_{k} \cdot\left(\alpha_{k}+\beta_{k} \sqrt{2} \rho^{1 / 2} e_{j}\right)\right) .
$$

In this expression, the first component in parentheses, $\sqrt{2} \rho^{1 / 2} e_{j}$, stands in for $u$. To complete the quadrature approximation to equation (B-7), we divide equation (B-10) by the approximation to $P\left(Z_{i}\right)$, which is

$$
\pi^{-1 / 2} \sum_{j=1}^{n_{q}} w_{j} \prod_{k=1}^{K} \Phi\left(z_{i k} r_{k} \cdot\left(\alpha_{k}+\beta_{k} \sqrt{2} \rho^{1 / 2} e_{j}\right)\right)
$$

These calculations are carried out using the estimated $\hat{\alpha}_{k}, \hat{\beta}_{k}$, and $\hat{\rho}$ parameters. (The factor $u$, being normally distributed, takes on negative as well as positive values. It may be that quadrature approximations to the conditional expectation of $u$ perform poorly unless the integrand $u P\left(u \mid Z_{i}\right)$ is positive. An easy solution is to add a large positive constant to $u$ [i.e., to its proxy $\sqrt{2} \rho^{1 / 2} e_{j}$ that appears immediately after the summation sign in equation (B-10)] and then subtract that constant after the integral has been calculated.)

\section{The multiple indicator, multiple cause model}

With all of this as background, we may now generalize things by allowing the unobserved factor to be determined by a set of observed exogenous variables $X_{i}$ as well as an unobserved component $u_{i}$. This MIMIC model ("multiple indicator, multiple cause") may be represented as $f_{i}=X_{i}^{\prime} \gamma+u_{i}$, where $f_{i}$ is the latent factor, the $X_{i}$ covariates are its observed 
determinants, and $u_{i}$ is its unobserved determinant, assumed to be independent of $X_{i}$. In this approach, the latent indicator $Z_{i k}^{*}$ is written out as

$$
\begin{aligned}
Z_{i k}^{*} & =\alpha_{k}+\beta_{k} f_{i}+v_{i k} \\
& =\alpha_{k}+\beta_{k} X_{i}^{\prime} \gamma+\beta_{k} u_{i}+v_{i k}
\end{aligned}
$$

We apply the unit variance restrictions as before,

$$
r_{k} Z_{i k}^{*}=r_{k}\left(\alpha_{k}+\beta_{k} X_{i}^{\prime} \gamma+\beta_{k} u_{i}\right)+r_{k} v_{i k}
$$

and obtain

$$
\ln P_{i j}=\sum_{k=1}^{K} \ln \Phi\left(z_{i k} r_{k}\left(\alpha_{k}+\beta_{k} X_{i}^{\prime} \gamma+\beta_{k} \sqrt{2} \rho^{1 / 2} e_{j}\right)\right),
$$

also much as before.

The forms of the scores in the $\alpha_{k}$ and $\beta_{k}$ dimensions are essentially unchanged. For the other parameters, however, we have

$$
\frac{\partial \ln P_{i j}}{\partial \gamma}=\sum_{k=1}^{K} \frac{\partial \ln P_{i j}}{\partial \alpha_{k}} \cdot \beta_{k} \cdot X_{i}
$$

a vector of the same dimension as the $X_{i}$ vector, and

$$
\frac{\partial \ln P_{i j}}{\partial \rho}=\frac{\partial \ln P_{i j}}{\partial \alpha_{k}} \cdot\left(W_{k j} r_{k}^{2} \beta_{k} \rho+X_{i}^{\prime} \gamma+\sqrt{2} \rho^{1 / 2} e_{j}\right)
$$

with $W_{k j}=\alpha_{k}+\beta_{k} X_{i}^{\prime} \gamma+\beta_{k} \sqrt{2} \rho^{1 / 2} e_{j}$. This definition of $W_{k j}$ would also be used in the modified versions of equations (B-4) and (B-5).

As for estimating the unobserved factor, there is little to distinguish the MIMIC model from the standard model. In this case we aim to estimate $f_{i}=X_{i}^{\prime} \gamma+u_{i}$ conditional on $Z_{i}$ and $X_{i}$. We employ $\hat{\gamma}$ for the first term and then apply the procedures that were outlined above to predict $u_{i}$. 


\section{NOTES}

1 See www.un.org/millenniumgoals for further information on the Millennium Declaration and its associated goals, specific targets, and research programs.

2 One of the most influential randomized interventions in the history of family planning, the Taichung experiment of 1963, found strong evidence of information diffusion along social network lines in this Taiwanese city (Freedman and Takeshita 1969). See Casterline (2001) for an excellent summary of related findings in several areas of demographic research.

3 There may well be a connection between local social capital and health services-Gilson (2003) applies the concept of "trust" to explain attitudes toward health care providers and institutions. The trust concept may provide one way of measuring the social dimensions of access to effective medical care.

4 According to Fred Arnold (personal communication), in developing countries the enumeration areas used in conducting censuses, which often provide the sampling frame for surveys, typically include 100-200 households. Their spatial extent varies. The logistics of survey-taking - the need for interviewers to conduct a given number of interviews per workday-may imply that urban clusters will generally be compact, especially in high residential density areas.

5 Note that no $\beta_{1}$ coefficient appears in the first of the indicator equations: It has been normalized to unity. Further normalizations are also required, as discussed in Appendix B. In latent variables models such as these, the sizes of the variances $\sigma_{u}^{2}$ and $\sigma_{v_{k}}^{2}$ are not identifiable. For the indicator equations, we apply the normalization rule $\beta_{k}^{2} \sigma_{u}^{2}+\sigma_{v_{k}}^{2}=1$ so that the variance of $\beta_{k} u+v_{k}$ equals unity in each equation.

6 As will be made clear, it is more accurate to describe the estimation method as "quasimaximum likelihood," because the estimating equations do not take cross-household, within-neighborhood correlations into account. Note that the full system, equations (1) and (2), can be viewed as a constrained version of a largish multivariate probit system. To see how estimation techniques for such binary indicator models differ from those for models with continuously valued indicators, compare Lawley and Maxwell (1962), Bollen (1989), and Jöreskog (2000, 2002). The maximization problem does present some numerical difficulties, and it appears that maximum-likelihood methods have been used less often in problems such as these than minimum-distance estimation.

7 As in other two-step models with "generated regressors," the standard errors of the estimators $\hat{\theta}$ and $\hat{\delta}$ should be corrected for the use of an estimated $\hat{f}$ in the second step. We employ robust standard errors, which should adequately address this and other sources of heteroskedasticity.

8 This assumes independence among $\left\{u, v_{1}, \ldots, v_{K}\right\}$. The $X$ variables themselves are taken to be fully exogenous.

9 Over the past year, however, the DHS has been experimenting with new urban-sensitive questions on housing ownership and security of tenure in a handful of surveys.

10 In most of our samples there is sufficient variation in headship for this strategy to produce distinct education variables in the indicator and health equations. 
11 One survey, for Yemen, provides data on durables and their determinants, but not on the health variables.

12 Although the majority of DHS have collected such information on children born in the last five years, we have set the upper limit on age to three years to make use of all available surveys with height data.

13 By construction, of course, only one-quarter of urban households in any survey are relatively poor, and only one-quarter are relatively affluent. The definition of poverty and affluence in terms of quartiles places some constraints on distributions like those seen in the figure. A complicating factor is that DHS sampling clusters vary in population size. A more refined analysis than we can undertake here would take such complications into account.

14 Fred Arnold and colleagues at the DHS have examined the case of Mumbai, India, where maps of survey enumeration areas can be overlaid on the maps of urban slum communities that have been drawn up by Indian planners and social scientists. He reports seeing many discrepancies between these two types of spatial units (personal communication). It is not yet known whether what is true for Mumbai is true more generally.

\section{REFERENCES}

Aber, J. L., Gephart, M. A., Brooks-Gunn, J., and Connell, J. P. (1997). Development in context: Implications for studying neighborhood effects. In Brooks-Gunn, J., Duncan, G. J., and Aber, J. L., editors, Neighborhood Poverty, volume I: Context and Consequences for Children, pages 44-61. Russell Sage Foundation, New York.

Åberg Yngwe, M., Fritzell, J., Lundberg, O., Diderichsen, F., and Burström, B. (2003). Exploring relative deprivation: Is social comparison a mechanism in the relation between income and health? Social Science and Medicine, 57(8):1463-1473.

African Population and Health Research Center (2002). Population and Health Dynamics in Nairobi's Informal Settlements: Report of the Nairobi Cross-Sectional Slums Survey (NCSS) 2000. African Population and Health Research Center, Nairobi.

Astone, N., Nathanson, C. A., Schoen, R., and Kim, Y. J. (1999). Family demography, social theory, and investment in social capital. Population and Development Review, 25(1):131.

Behrman, J., Kohler, H.-P., and Watkins, S. (2001). Social networks, family planning, and worrying about AIDS. Paper presented at the 2001 Annual Meetings of the Population Association of America, Washington, DC, 29-31 March.

Bollen, K. (1989). Structural Equations with Latent Variables. John Wiley \& Sons, New York.

Caldeira, T. P. R. (1999). Fortified enclaves: The new urban segregation. In Holston, J., editor, Cities and Citizenship, pages 114-138. Duke University Press, Durham and London. 
Caldeira, T. P. R. (2000). City of Walls: Crime, Segregation, and Citizenship in São Paulo. University of California Press, Berkeley, CA.

Casterline, J. B., editor (2001). Diffusion Processes and Fertility Transition: Selected Perspectives. National Academies Press, Washington, DC.

Casterline, J. B., Montgomery, M. R., Agyeman, D. K., Aglobitse, P., and Kiros, G.-E. (2001). Social networks and contraceptive dynamics in southern Ghana. Paper presented at the 2001 Annual Meetings of the Population Association of America, Washington, DC, 29-31 March.

Casterline, J. B. and Sinding, S. W. (2000). Unmet need for family planning in developing countries and implications for population policy. Population and Development Review, 26(4):691-723.

Coleman, J. S. (1988). Social capital in the creation of human capital. American Journal of Sociology, 94(supplement):S95-S120.

Coulton, C., Korbin, J., Chan, T., and Su, M. (1997). Mapping residents' perceptions of neighborhood boundaries: A methodological note. Working Paper, Center on Urban Poverty and Social Change. Case Western Reserve University, Cleveland, OH.

Drukker, M., Kaplan, C., Feron, F., and van Os, J. (2003). Children's health-related quality of life, neighbourhood socio-economic deprivation and social capital. A contextual analysis. Social Science and Medicine, 57(5):825-841.

Ferguson, B. D., Tandon, A., Gakidou, E., and Murray, C. J. L. (2003). Estimating permanent income using indicator variables. Global Programme on Evidence for Health Policy Discussion Paper no. 42. World Health Organization, Geneva.

Filmer, D. and Pritchett, L. (1999). The effect of household wealth on educational attainment: Evidence from 35 countries. Population and Development Review, 25(1):85-120.

Filmer, D. and Pritchett, L. (2001). Estimating wealth effects without expenditure dataor tears: An application to educational enrollments in states of India. Demography, 38(1):115-132.

Freedman, R. and Takeshita, J. Y. (1969). Family Planning in Taiwan: An Experiment in Social Change. Princeton University Press, Princeton, NJ.

Furstenberg, F. F. (1993). How families manage risk and opportunity in dangerous neighborhoods. In Wilson, W. J., editor, Sociology and the Public Agenda, pages 231-258. Sage Publications, Newbury Park, CA. 
Furstenberg, F. F. and Hughes, M. E. (1997). The influence of neighborhoods on children's development: A theoretical perspective and a research agenda. In Brooks-Gunn, J., Duncan, G. J., and Aber, J. L., editors, Neighborhood Poverty, volume II: Policy Implications in Studying Neighborhoods, pages 23-47. Russell Sage Foundation, New York.

Gilson, L. (2003). Trust and the development of health care as a social institution. Social Science and Medicine, 56(7):1453-1468.

Ginther, D., Haveman, R., and Wolfe, B. (2000). Neighborhood attributes as determinants of children's outcomes: How robust are the relationships? Journal of Human Resources, 35(4):603-633.

Harpham, T. and Tanner, M., editors (1995). Urban Health in Developing Countries: Progress and Prospects. St. Martin's Press, New York.

Heckman, J. J. (1981). Statistical models for discrete panel data. In Manski, C. F. and McFadden, D., editors, Structural Analysis of Discrete Data with Econometric Applications, pages 114-178. MIT Press, Cambridge, MA.

Herr, H. and Karl, G. (2002). Estimating global slum dwellers: Monitoring the Millennium Development Goal 7, Target 11. Monitoring Systems Branch, Global Urban Observatory. UN-HABITAT, Nairobi.

Herr, H. and Mboup, G. (2003). Slum dweller estimation methodology. Unpublished paper (in progress). UN-HABITAT, Nairobi.

Jöreskog, K. G. (2000). Latent variable scores and their uses. Unpublished paper, available at http://www.ssicentral.com/lisrel.column6.pdf.

Jöreskog, K. G. (2002). Structural equation modeling with ordinal variables using LISREL. Unpublished paper, available at http://www.ssicentral.com/lisrel/corner.htm.

Kaufman, C. E., Clark, S., Manzini, N., and May, J. (2002). How community structures of time and opportunity shape adolescent sexual behavior in South Africa. Policy Research Division Working Paper no. 159. Population Council, New York.

Kravdal, Ø. (2003). Community mortality in India: Individual and community effects of women's education and autonomy. East-West Center Working Papers, Population Series, no. 112. East-West Center, Honolulu, HI.

Lawley, D. N. and Maxwell, A. E. (1962). Factor analysis as a statistical method. Statistician, 12(3):209-229. 
Massey, D. S. (1990). American apartheid: Segregation and the making of the underclass. American Journal of Sociology, 96(2):329-357.

Massey, D. S. (1996). The age of extremes: Concentrated affluence and poverty in the twentyfirst century. Demography, 33(4):395-412.

McCulloch, A. (2003). An examination of social capital and social disorganisation in neighbourhoods in the British household panel study. Social Science and Medicine, 56(7):1425-1438.

McDade, T. W. and Adair, L. S. (2001). Defining the 'urban' in urbanization and health: A factor analysis approach. Social Science and Medicine, 53(1):55-70.

Montgomery, M. R., Gragnolati, M., Burke, K. A., and Paredes, E. (2000). Measuring living standards with proxy variables. Demography, 37(2):155-174.

Montgomery, M. R., Lloyd, C., Hewett, P. C., and Heuveline, P. (1997). The consequences of imperfect fertility control for children's survival, health, and schooling. Demographic and Health Surveys Analytical Reports no. 7. Macro International, Inc., Calverton, MD.

Panel on Urban Population Dynamics (2003). Cities Transformed: Demographic Change and Its Implications in the Developing World. National Academies Press, Washington, DC. Montgomery, M. R., Stren, R., Cohen, B., and Reed, H., editors.

Pebley, A. R., Goldman, N., and Rodríguez, G. (1996). Prenatal and delivery care and childhood immunization in Guatemala: Do family and community matter? Demography, 33(2):231-247.

Pebley, A. R. and Sastry, N. (2003). Concentrated poverty vs. concentrated affluence: Effects on neighborhood social environments and children's outcomes. Paper presented at the 2003 Annual Meetings of the Population Association of America, Minneapolis, MN, 1-3 May.

Press, W. H., Teukolsky, S. A., Vetterling, W. T., and Flannery, B. P. (1992). Numerical Recipes in FORTRAN: The Art of Scientific Computing. Cambridge University Press, New York.

Press, W. H., Teukolsky, S. A., Vetterling, W. T., and Flannery, B. P. (1996). Numerical Recipes in Fortran 90: The Art of Parallel Scientific Computing, volume 2. Cambridge University Press, New York.

Sahn, D. E. and Stifel, D. C. (2000). Poverty comparisons over time and across countries in Africa. World Development, 28(12):2123-2155. 
Sampson, R. J., Morenoff, J. D., and Gannon-Rowley, T. (2002). Assessing 'neighborhood effects': Social processes and new directions in research. Annual Review of Sociology, 28:443-478.

Sastry, N. (1996). Community characteristics, individual and household attributes, and child survival in Brazil. Demography, 33(2):211-229.

Sastry, N., Pebley, A., and Zonta, M. (2002). Neighborhood definitions and the spatial dimension of daily life in Los Angeles. Paper presented at the 2002 Annual Meetings of the Population Association of America, Atlanta, GA, 9-11 May.

Szwarcwald, C. L., de Andrade, C. L. T., and Bastos, F. I. (2002). Income inequality, residential poverty clustering and infant mortality: A study in Rio de Janeiro, Brazil. Social Science and Medicine, 55(12):2083-2092.

Tandon, A., Gakidou, E., Murray, C. J. L., and Ferguson, B. (2002). Cross-population comparability and PPPs: Using micro-data on indicators of consumer durables. Evidence and Information for Policy Cluster draft paper. World Health Organization, Geneva.

Timæus, I. M. and Lush, L. (1995). Intra-urban differentials in child health. Health Transition Review, 5(2):163-190.

United Nations (2000). World Urbanization Prospects: The 1999 Revision: Data Tables and Highlights. United Nations, Department of Economic and Social Affairs, Population Division, New York.

van den Eeden, P. and Hüttner, H. J. M. (1982). Multi-level research. Current Sociology, 30(3):1-182.

Wellman, B. and Leighton, B. (1979). Networks, neighborhoods, and communities: Approaches to the study of the community question. Urban Affairs Quarterly, 14(3):363390.

Wen, M., Browning, C. R., and Cagney, K. A. (2003). Poverty, affluence, and income inequality: Neighborhood economic structure and its implications for health. Social Science and Medicine, 57(5):843-860.

Westoff, C. F. and Bankole, A. (1995). Unmet Need 1990-1994. Demographic and Health Surveys Comparative Studies. Macro International, Inc., Calverton, MD.

Westoff, C. F. and Pebley, A. R. (1981). Alternative measures of unmet need for family planning in developing countries. International Family Planning Perspectives, 7(4):126136. 
White, M. J. (2001). Residential concentration/segregation, demographic effects of. In Smelser, N. J. and Baltes, P. B., editors, International Encyclopedia of the Social and Behavioral Sciences, volume 19, pages 13250-13254. Elsevier Science, Oxford.

Wilkinson, R. G. (1996). Unhealthy Societies: The Afflictions of Inequality. Routledge, London.

Wilson, W. J. (1987). The Truly Disadvantaged: The Inner City, the Underclass and Public Policy. University of Chicago Press, Chicago, IL. 


\section{POLICY DIVISION WORKING PAPERS}

If still in print, single copies of up to three working papers from 1989 through 2003 are available free of charge.

Beginning with the 2004 issues, the working papers will no longer be available in print format. Instead they will be distributed electronically. As each new paper is completed subscribers will be notified by e-mail and a link to the paper will be provided.

To subscribe to the Policy Research Division working paper e-mail notification list, or to obtain back issues from 1989 to 2003, please send your request to prdwp@ popcouncil.org.

PDFs of recent issues are available at www.popcouncil.org/publications/wp/prd/rdwplist.html

2004

184 Mark R. Montgomery and Paul C. Hewett. "Urban poverty and health in developing countries: Household and neighborhood effects."

\section{3}

183 Agnes R. Quisumbing and Kelly Hallman. "Marriage in transition: Evidence on age, education, and assets from six developing countries."

182 Paul C. Hewett, Barbara S. Mensch, and Annabel S. Erulkar, "Consistency in the reporting of sexual behavior among adolescent girls in Kenya: A comparison of interviewing methods."

181 Zachary Zimmer, Linda G. Martin, and Hui-Sheng Lin, "Determinants of old-age mortality in Taiwan."
180 Frank K. Nyonator, J. Koku Awoonor-Williams, James F. Phillips, Tanya C. Jones, and Robert A. Miller, "The Ghana Community-based Health Planning and Services Initiative: Fostering evidence-based organizational change and development in a resourceconstrained setting."

179 John Bongaarts and Griffith Feeney, "Estimating mean lifetime."

178 Elizabeth F. Jackson, Patricia Akweongo, Evelyn Sakeah, Abraham Hodgson, Rofina Asuru, and James F. Phillips, "Women's denial of having experienced female genital cutting in northern Ghana: Explanatory factors and consequences for analysis of survey data."

177 John Bongaarts, "Completing the fertility transition in the developing world: The role of educational differences and fertility preferences."

* No longer available as a printed publication. Download electronic file from Web site only. 
176 Cynthia B. Lloyd and Paul C. Hewett, "Primary schooling in sub-Saharan Africa: Recent trends and current challenges."

175 James F. Phillips, Tanya C. Jones, Frank K. Nyonator, and Shruti Ravikumar, "Evidence-based development of health and family planning programs in Bangladesh and Ghana."

174 Geoffrey McNicoll, "Population and development: An introductory view."

173 Paul Demeny, "Population policy: A concise summary."

172 Zachary Zimmer, Napaporn Chayovan, Hui-Sheng Lin, and Josefina Natividad, "How indicators of socioeconomic status relate to physical functioning of older adults in three Asian societies."

171 Sajeda Amin and Nagah H. AlBassusi, "Wage work and marriage: Perspectives of Egyptian working women."

170 Ravai Marindo, Steve Pearson, and John B. Casterline, "Condom use and abstinence among unmarried young people in Zimbabwe: Which strategy, whose agenda?"

169 Zachary Zimmer and Julia Dayton, "The living arrangements of older adults in sub-Saharan Africa in a time of HIV/AIDS."
168 Paul C. Hewett, Annabel S. Erulkar, and Barbara S. Mensch, "The feasibility of computerassisted survey interviewing in Africa: Experience from two rural districts in Kenya."

2002

167* Dominic K. Agyeman and John B. Casterline, "Social organization and reproductive behavior in southern Ghana."

166* Carol E. Kaufman and Stavros E. Stavrou, "'Bus fare, please': The economics of sex and gifts among adolescents in urban South Africa."

165 Kelly Hallman, Agnes R. Quisumbing, Marie Ruel, and Bénédicte de la Brière, "Childcare, mothers' work, and earnings: Findings from the urban slums of Guatemala City."

164 Cynthia B. Lloyd, Cem Mete, and Zeba A. Sathar, "The effect of gender differences in primary school access, type, and quality on the decision to enroll in rural Pakistan.”

163 Barbara S. Mensch, Wesley H. Clark, and Dang Nguyen Anh, "Premarital sex in Vietnam: Is the current concern with adolescent reproductive health warranted?"

162 Naomi Rutenberg, Carol E. Kaufman, Kate Macintyre, Lisanne Brown, and Ali Karim, "Pregnant or positive: Adolescent childbearing and HIV risk in South Africa."

* No longer available as a printed publication. Download electronic file from Web site only. 
161 John Bongaarts, "The end of the fertility transition in the developing world."

160* Julia Dayton and Martha Ainsworth, "The elderly and AIDS: Coping strategies and health consequences in rural Tanzania."

159 Carol E. Kaufman, Shelley Clark, Ntsiki Manzini, and Julian May, "How community structures of time and opportunity shape adolescent sexual behavior in South Africa."
158 Geoffrey McNicoll, "Demographic factors in East Asian regional integration."

157 Zachary Zimmer and Sovan Kiry Kim, "Living arrangements and socio-demographic conditions of older adults in Cambodia."

156 John Bongaarts and Griffith Feeney, "How long do we live?"

155 Zachary Zimmer, Linda G. Martin, and Ming-Cheng Chang, "Changes in functional limitations and survival among the elderly in Taiwan: 1993, 1996, and 1999."

* No longer available as a printed publication. Download electronic file from Web site only. 